\title{
BUSINESS CYCLE \\ DYNAMICS UNDER RATIONAL INATTENTION
}

by Bartosz Maćkowiak and Mirko Wiederholt 


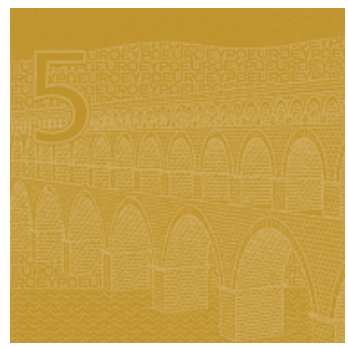

\title{
WORKING PAPER SERIES
}

NO I33I / APRIL 20II

\section{BUSINESS CYCLE DYNAMICS \\ UNDER RATIONAL INATTENTION'}

\author{
by Bartosz Maćkowiak² \\ and Mirko Wiederholt ${ }^{3}$
}
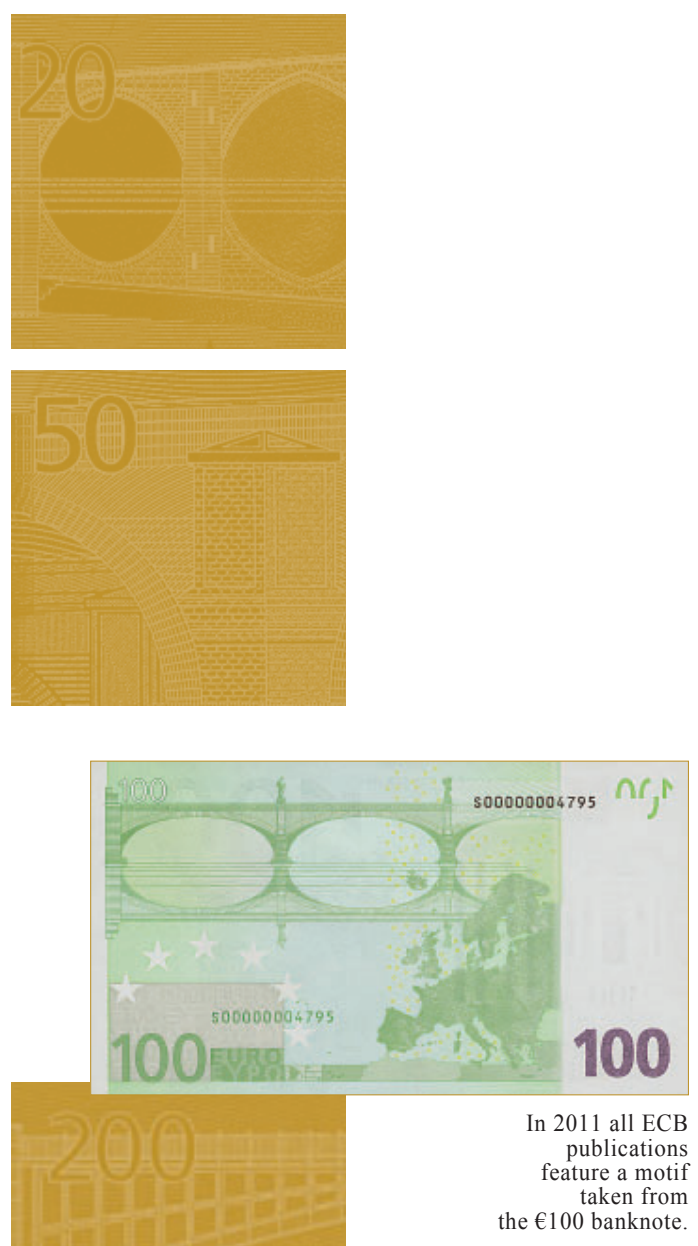

NOTE: This Working Paper should not be reported as representing the views of the European Central Bank (ECB).

The views expressed are those of the authors and do not necessarily reflect those of the $E C B$.

This paper can be downloaded without charge from http://www.ecb.europa.eu or from the Social Science Research Network electronic library at http://ssrn.com/abstract_id=1804852.

I We thank for helpful comments: Paco Buera, Larry Christiano, James Costain, Martin- Eichenbaum, Christian Hellwig, Marek Jarociński, Giorgio Primiceri, Chris Sims, Bruno Strulovici, Andrea Tambalotti and seminar and conference participants at Amsterdam, Bank of Canada, Bonn, Carlos III, Chicago Fed, Columbia, Cowles Foundation Summer Conference 2009, DePaul, Duke, Einaudi Institute, European Central Bank, ESSIM 2008, EUI, Harvard, LSE, Madison, Mannheim, MIT, Minneapolis Fed, Minnesota Workshop in Macroeconomic Theory 2009, NBER Summer Institute 2008, NYU, NAWMES 2008, Philadelphia Fed, Pompeu Fabra, Princeton, Richmond Fed, Riksbank, SED 2008, Stony Brook, Toronto, Toulouse, UCSD,

University of Chicago, University of Hong Kong, University of Montreal, Wharton and Yale.

2 CEPR and European Central Bank, Kaiserstrasse 29, D-603/I Frankfurt am Main, Germany; e-mail: bartosz.mackowiak@ecb.europa.eu 3 Department of Economics, Northwestern University, 200I Sheridan Road, Evanston, IL 60208, USA; 
(C) European Central Bank, 2011

\section{Address}

Kaiserstrasse 29

60311 Frankfurt am Main, Germany

Postal address

Postfach 160319

60066 Frankfurt am Main, Germany

Telephone

+496913440

Internet

http://www.ecb.europa.eu

Fax

+496913446000

All rights reserved.

Any reproduction, publication and reprint in the form of a different publication, whether printed or produced electronically, in whole or in part, is permitted only with the explicit written authorisation of the ECB or the authors.

Information on all of the papers published in the ECB Working Paper Series can be found on the ECB's website, http://www. ecb.europa.eu/pub/scientific/wps/date/ html/index.en.html

ISSN 1725-2806 (online) 


\section{CONTENTS}

Abstract 4

Non-technical summary 5

1 Introduction 7

2 Model setup I3

2.1 Households 13

2.2 Firms I4

2.3 Government 15

2.4 Shocks 16

2.5 Notation 17

3 Derivation of the firms' objective 17

4 Derivation of the households' objective 22

5 Aggregation 27

6 Solution under perfect information 28

7 Rational inattention by firms 30

7.1 The attention problem of the decision-maker in a firm $\quad 30$

7.2 Computing the equilibrium of the model 34

7.3 Benchmark parameter values and solution 36

7.4 The effects of changes in parameter values $4 \mathrm{I}$

7.5 Extension: signals 43

8 Rational inattention by households and firms $\quad 47$

8.1 The attention problem of a household 48

8.2 Computing the equilibrium of the model 52

8.3 Benchmark parameter values and solution 52

8.4 The effects of changes in parameter values 56

8.5 Extension: households set nominal wage rates 57

9 Conclusion 58

Appendix 59

References 61

Figures $\quad 65$ 


\begin{abstract}
We develop a dynamic stochastic general equilibrium model with rational inattention by households and firms. Consumption responds slowly to interest rate changes because households decide to pay little attention to the real interest rate. Prices respond quickly to some shocks and slowly to other shocks. The mix of fast and slow responses of prices to shocks matches the pattern found in the empirical literature. Changes in the conduct of monetary policy yield very different outcomes than in models currently used at central banks because systematic changes in policy cause reallocation of attention by decision-makers in households and firms.
\end{abstract}

Keywords: information choice, rational inattention, monetary policy, business cycles. (JEL: D83, E31, E32, E52). 


\section{NON-TECHNICAL SUMMARY}

The idea of rational inattention is that decision-makers have a limited amount of attention and decide how to allocate their attention. This paper develops a dynamic stochastic general equilibrium (DSGE) model with rational inattention by households and firms. We are motivated by the question of how to model the inertia found in macroeconomic data. Standard DSGE models used for policy analysis match this inertia by introducing multiple sources of slow adjustment: Calvo price setting, habit formation in consumption, Calvo wage setting, and other sources in richer models. We pursue the alternative idea that the inertia found in macroeconomic data can be understood as the result of one source of slow adjustment: rational inattention, that is, deliberate inattention by decision-makers as the outcome of a choice problem. Moreover, the degree of slow adjustment is endogenous because when the environment changes the allocation of attention changes.

We summarise the model's predictions in four points. The first prediction of the model is that consumption responds very slowly to interest rate changes because households decide to pay little attention to movements in the real interest rate. This finding is important because in a large class of models monetary policy affects the real economy through the following channel. The central bank changes the nominal interest rate; due to some form of sticky prices the real interest rate changes; and households respond with their consumption to the change in the real interest rate. Our model predicts that the last part of this channel will be very slow, that is, the model predicts that consumption will respond very slowly to a change in the real interest rate. This is what the empirical literature finds. Moreover, our finding that households choose to pay little attention to movements in the real interest rate holds for low and high values of the coefficient of relative risk aversion.

The second prediction of the model is that prices respond quickly to some shocks and slowly to other shocks. The mix of quick and slow responses of prices to shocks matches the pattern found in the empirical literature. Specifically, the model predicts that prices respond very quickly to market-specific shocks, fairly quickly to aggregate technology shocks, and slowly to monetary policy shocks. The reason is the following. When we calibrate the model so as to match key features of the U.S. data like the large average absolute size of price changes in micro data and the small variance of the innovation in the Taylor rule, most of the variation in the profitmaximizing price is due to market-specific shocks, considerable variation in the profit-maximizing price is due to aggregate technology shocks, and little variation in the profit-maximizing price is due to monetary policy shocks. Decision-makers in firms who have to set prices thus pay close attention to market-specific conditions, some attention to aggregate technology, and little attention to monetary policy. Prices therefore respond very quickly to market-specific shocks, fairly quickly to aggregate technology shocks, and slowly to monetary policy shocks.

The third set of predictions of the model concern how households and firms interact in general equilibrium under rational inattention. To understand this interaction, we first solve the model with rational inattention by firms only and we then add rational inattention by households. We find that adding rational inattention by households has the following implications for aggregate dynamics. First, since households decide to pay little attention to movements in the real interest rate, the impulse response of 
consumption to a monetary policy shock becomes hump-shaped. Second, since consumption now responds less and more slowly to monetary policy shocks, decisionmakers in firms choose to pay even less attention to monetary policy. Prices therefore respond even more slowly to monetary policy shocks. In summary, households' optimal allocation of attention affects firms' optimal allocation of attention.

The fourth prediction is that the outcomes of experiments in this DSGE model with rational inattention are very different than in DSGE models currently used for monetary policy analysis. Moreover, there is a clear intuition for why the outcomes are different: the allocation of attention varies with the economic environment. Consider an example. Since monetary policy is described by a Taylor rule (i.e., a policy rule stating that the nominal interest rate is a function of inflation and a measure of economic activity), one can ask the following question. What happens when the central bank fights inflation more aggressively? In other words, what happens when the central bank raises the interest rate more strongly in response to inflation? In the Calvo model, increasing the coefficient on inflation in the Taylor rule reduces the variance of the output gap, where the output gap is defined as the difference between output and the efficient level of output. This feature of the Calvo model is important, because this feature underlies the conventional wisdom that fighting inflation more aggressively moves the economy closer to the efficient level of output. By contrast, in the rational inattention model there is a non-monotonic relationship between the coefficient on inflation in the Taylor rule and the variance of the output gap. In our benchmark economy the following happens. When the central bank increases the coefficient on inflation in the Taylor rule, the variance of the output gap due to aggregate technology shocks first rises and then falls, and the variance of the output gap due to monetary policy shocks increases. The reason for the different outcomes is that in the rational inattention model there is an additional effect. When the central bank stabilizes the price level more, decision-makers in firms decide to pay less attention to aggregate conditions. As a result, the model yields an outcome that is very different from the conventional wisdom derived from DSGE models currently used at central banks. 


\section{Introduction}

Economists have studied for a long time how decision-makers allocate scarce resources. The recent literature on rational inattention studies how decision-makers allocate the scarce resource attention. The idea of rational inattention is that decision-makers have a limited amount of attention and decide how to allocate their attention. This paper develops a dynamic stochastic general equilibrium (DSGE) model with rational inattention by households and firms. Following Sims (2003), we model limited attention as a constraint on information flow and we let decision-makers in households and firms choose information flows subject to the constraint on information flow. For example, consider a household that has to decide how much to consume and which goods to consume. To take the optimal consumption-saving decision and to buy the optimal consumption basket, the household has to know the real interest rate and the prices of all consumption goods. The idea of rational inattention applied to this example is that: knowing the real interest rate and the prices of all consumption goods requires attention; households have a limited amount of attention; and households choose themselves how to allocate their attention. We study the implications of rational inattention for business cycle dynamics.

We are motivated by the question of how to model the inertia found in macroeconomic data. Standard DSGE models used for policy analysis match this inertia by introducing multiple sources of slow adjustment: Calvo price setting, habit formation in consumption, Calvo wage setting, and other sources in richer models. ${ }^{1}$ We pursue the alternative idea that the inertia found in macroeconomic data can be understood as the result of one source of slow adjustment: rational inattention, that is, deliberate inattention by decision-makers as the outcome of a choice problem. Moreover, the degree of slow adjustment is endogenous because when the environment changes the allocation of attention changes.

We model an economy with many households, many firms, and a government. Firms produce differentiated goods with a variety of types of labor. Households consume the variety of goods, supply the differentiated types of labor, and hold nominal government bonds. Firms take price setting and labor mix decisions, while households take consumption and wage setting decisions. The central bank sets the nominal interest rate according to a Taylor rule. The economy is affected by aggregate technology shocks, monetary policy shocks, and firm-specific productivity shocks. The

\footnotetext{
${ }^{1}$ See, for example, Woodford (2003), Christiano, Eichenbaum and Evans (2005), and Smets and Wouters (2007).
} 
only source of slow adjustment is rational inattention by decision-makers in firms and households. We compute the rational expectations equilibrium of the model.

We summarize the model's predictions in four points. The first prediction of the model is that consumption responds very slowly to interest rate changes because households decide to pay little attention to movements in the real interest rate. This finding is important because in a large class of models monetary policy affects the real economy through the following channel. The central bank changes the nominal interest rate; due to some form of sticky prices the real interest rate changes; and households respond with their consumption to the change in the real interest rate. Our model predicts that the last part of this channel will be very slow, that is, the model predicts that consumption will respond very slowly to a change in the real interest rate. This is what the empirical literature finds. ${ }^{2}$ Moreover, our finding that households choose to pay little attention to movements in the real interest rate holds for low and high values of the coefficient of relative risk aversion. The reasons are the following. For low values of the coefficient of relative risk aversion, deviations from the consumption Euler equation are cheap in utility terms. For high values of the coefficient of relative risk aversion, the coefficient on the real interest rate in the consumption Euler equation is small. This implies that households do not want to respond strongly to changes in the real interest rate anyway. Therefore, for low and high values of the coefficient of relative risk aversion, imperfect tracking of the real interest rate causes only small utility losses. Hence, households decide to pay little attention to movements in the real interest rate.

The second prediction of the model is that prices respond quickly to some shocks and slowly to other shocks. The mix of quick and slow responses of prices to shocks matches the pattern found in the empirical literature. Specifically, the model predicts that prices respond very quickly to marketspecific shocks, fairly quickly to aggregate technology shocks, and slowly to monetary policy shocks. The reason is the following. When we calibrate the model so as to match key features of the U.S.

\footnotetext{
${ }^{2}$ The literature on structural vector autoregressions finds that consumption shows a slow, hump-shaped response to a monetary policy shock. See, for example, Leeper, Sims and Zha (1996). The literature on standard DSGE models used for policy analysis finds that the fit of those models to macroeconomic data is maximized when the degree of habit formation in consumption is large. See, for example, Justiniano and Primiceri (2008). With a large degree of habit formation, consumption responds very slowly to a change in the real interest rate. Our model suggests that the observed slow response of consumption to the real interest rate is the outcome of a decision problem by households with standard preferences.
} 
data like the large average absolute size of price changes in micro data and the small variance of the innovation in the Taylor rule, most of the variation in the profit-maximizing price is due to market-specific shocks, considerable variation in the profit-maximizing price is due to aggregate technology shocks, and little variation in the profit-maximizing price is due to monetary policy shocks. Decision-makers in firms who have to set prices thus pay close attention to market-specific conditions, some attention to aggregate technology, and little attention to monetary policy. Prices therefore respond very quickly to market-specific shocks, fairly quickly to aggregate technology shocks, and slowly to monetary policy shocks. Interestingly, the empirical literature finds in the data the same pattern of quick and slow responses of prices to shocks: Boivin, Giannoni and Mihov (2009) and Maćkowiak, Moench and Wiederholt (2009) find that prices respond very quickly to disaggregate shocks; Altig, Christiano, Eichenbaum and Linde (2005) find that the price level responds fairly quickly to aggregate technology shocks; and Christiano, Eichenbaum and Evans (1999), Leeper, Sims and Zha (1996) and Uhlig (2005) find that the price level responds slowly to monetary policy shocks. This mix of quick and slow responses of prices to shocks is difficult to match with DSGE models currently used for monetary policy analysis (e.g., the Calvo model). In an earlier paper, we present a model of price setting under rational inattention by firms that yields a quick response of prices to idiosyncratic shocks and a slow response of prices to aggregate shocks. ${ }^{3}$ One new insight here is that distinguishing between different types of aggregate shocks (aggregate technology shocks and monetary policy shocks) yields differential speeds of response of prices to different aggregate shocks that are consistent with the empirical findings cited above. Another new insight here is that these differential speeds of response of prices to shocks arise both when decision-makers in firms pay attention to the driving exogenous processes and when decision-makers in firms pay attention to endogenous variables like the price level, sales, and the wage bill.

In our model and in any other model with a price setting friction, firms experience profit losses due to deviations of the price from the profit-maximizing price. One nice feature of our model is that those profit losses due to deviations of the price from the profit-maximizing price are small. For comparison, in our benchmark economy profit losses due to deviations of the price from the profit-maximizing price are 30 times smaller than in the Calvo model that generates the same real effects of monetary policy shocks. The main reason is that in our model prices respond slowly to

\footnotetext{
${ }^{3}$ See Maćkowiak and Wiederholt (2009).
} 
monetary policy shocks, but quickly to market-specific and aggregate technology shocks. The other reason is that under rational inattention deviations of the price from the profit-maximizing price are less likely to be extreme than in the Calvo model.

The third set of predictions of the model concern how households and firms interact in general equilibrium under rational inattention. To understand this interaction, we first solve the model with rational inattention by firms only and we then add rational inattention by households. We find that adding rational inattention by households has the following implications for aggregate dynamics. First, since households decide to pay little attention to movements in the real interest rate, the impulse response of consumption to a monetary policy shock becomes hump-shaped. Second, since consumption now responds less and more slowly to monetary policy shocks, decision-makers in firms choose to pay even less attention to monetary policy. Prices therefore respond even more slowly to monetary policy shocks. In summary, households' optimal allocation of attention affects firms' optimal allocation of attention.

The fourth set of predictions concern policy experiments. Changes in the conduct of monetary policy yield very different outcomes in this DSGE model than in DSGE models currently used at central banks. This is because systematic changes in policy cause reallocation of attention by decision-makers in firms and households. Here we would like to highlight one important example. Since monetary policy is described by a Taylor rule (i.e., a policy rule stating that the nominal interest rate is a function of inflation and a measure of economic activity), one can ask the following question. What happens when the central bank fights inflation more aggressively? In other words, what happens when the central bank raises the interest rate more strongly in response to inflation? In the Calvo model, increasing the coefficient on inflation in the Taylor rule reduces the variance of the output gap, where the output gap is defined as the difference between output and the efficient level of output. This feature of the Calvo model is important, because this feature underlies the conventional wisdom that fighting inflation more aggressively moves the economy closer to the efficient level of output. By contrast, in the rational inattention model there is a non-monotonic relationship between the coefficient on inflation in the Taylor rule and the variance of the output gap. In our benchmark economy the following happens. When the central bank increases the coefficient on inflation in the Taylor rule, the variance of the output gap due to aggregate technology shocks first rises and then falls, and the variance of the output gap due to monetary policy shocks increases. 
The reason for the different outcomes is that in the rational inattention model there is an additional effect. When the central bank stabilizes the price level more, decision-makers in firms decide to pay less attention to aggregate conditions. As a result, the model yields an outcome that is very different from the conventional wisdom derived from DSGE models currently used at central banks.

Other experiments also yield very different outcomes than in other DSGE models. Another conventional wisdom derived from models currently used for monetary policy analysis is that raising strategic complementarity in price setting increases real effects of monetary policy shocks. A common way to raise strategic complementarity in price setting is to make a firm's marginal cost curve more upward sloping in own output. See, for example, Altig, Christiano, Eichenbaum and Linde (2005). When we raise strategic complementarity in price setting by making a firm's marginal cost curve more upward sloping in own output, we find that, for reasonable parameter values, real effects of monetary policy shocks become smaller not larger. The reason is that in the rational inattention model there is an additional effect. When the marginal cost curve becomes more upward sloping in own output, the cost of a price setting mistake of a given size increases. Decision-makers in firms therefore decide to pay more attention to the price setting decision, implying that prices respond faster to shocks. This additional effect dominates for reasonable parameter values and thus real effects of monetary policy shocks become smaller not larger.

To recapitulate, the outcomes of experiments in this DSGE model with rational inattention are very different than in DSGE models currently used for monetary policy analysis. Moreover, there is a clear intuition for why the outcomes are different: the allocation of attention varies with the economic environment.

This paper is related to the literature on rational inattention (e.g., Sims (2003, 2006), Luo (2008), Maćkowiak and Wiederholt (2009), Woodford (2009), Van Nieuwerburgh and Veldkamp (2009, 2010), Kacperczyk, Van Nieuwerburgh and Veldkamp (2010), Matejka (2010) and Mondria (2010)). ${ }^{4}$ There are two important differences to the existing literature on rational inattention. First, this paper develops the first dynamic stochastic general equilibrium (DSGE) model with rational inattention. Maćkowiak and Wiederholt (2009) is an equilibrium model of price setting under rational inattention by firms. The demand side of the economy is an exogenous process for nominal spending. This means that one cannot study the allocation of attention by households,

\footnotetext{
${ }^{4}$ See Sims (2010) or Veldkamp (2010) for a review of the literature on rational inattention.
} 
one cannot study the interaction between households and firms, and one cannot conduct the kind of monetary policy experiments that central banks are interested in (e.g., what happens when the central bank fights inflation more aggressively). Setting up and solving a DSGE model with rational inattention is not trivial. One has to specify how agents with rational inattention interact in markets. We suppose that in each market one side of the market chooses the price and the other side of the market chooses the quantity. Furthermore, households' optimal allocation of attention affects firms' optimal allocation of attention, and vice versa. Computing the equilibrium of the model therefore amounts to solving a non-trivial fixed point problem. Paciello (2010) solves a general equilibrium model with rational inattention by firms analytically. The main differences are that in his model households have perfect information and the model is static in the sense that: (i) all exogenous processes are white noise processes, (ii) the price level instead of inflation appears in the Taylor rule, and (iii) there is no lagged interest rate in the Taylor rule. Second, this paper studies consumption by households with rational inattention when the real interest rate fluctuates. Sims (2003, 2006), Luo (2008) and Tutino (2009) also study consumption-saving decisions under rational inattention but in these papers the real interest rate is constant. Therefore, the point that households have little incentive to track movements in the real interest rate (for low and high values of the coefficient of relative risk aversion) is not in those papers. This point is important because in a large class of models monetary policy affects the real economy through the following channel. The central bank changes the nominal interest rate; due to some form of price stickiness the real interest rate changes; and households respond with their consumption to the change in the real interest rate. If this is indeed the channel through which monetary policy affects the real economy, then the attention that households devote to the real interest rate is crucial.

The paper is also related to the literature on business cycle models with imperfect information (e.g., Lucas (1972), Woodford (2002), Mankiw and Reis (2002), Angeletos and La'O (2009a, 2009b) and Lorenzoni (2009)). The main difference to this literature is that in our model decision-makers choose the information structure (i.e., the information structure is derived from an objective and a set of constraints). This has two implications. First, the model gives an explanation for the equilibrium information structure. Second, the model predicts how the equilibrium information structure varies with policy. The fact that the equilibrium information structure varies with policy has important implications for the outcome of policy experiments. 
The paper is organized as follows. Section 2 describes all features of the economy apart from the attention problem of decision-makers. Sections 3 and 4 derive the objectives that decision-makers in firms and households maximize when they decide how to allocate their attention. Section 5 discusses aggregation. Section 6 presents the analytical solution of the model under perfect information. Section 7 states the attention problem of the decision-maker in a firm and presents solutions of the model with rational inattention by firms and perfect information by households. Section 8 states the attention problem of a household and presents solutions of the model with rational inattention by households and firms. Section 9 concludes.

\section{$2 \quad$ Model setup}

In this section we describe all features of the economy apart from information flows. Thereafter, we solve the model for alternative assumptions about information flows: (i) perfect information, (ii) rational inattention by firms, and (iii) rational inattention by households and firms.

In the model, there are three types of agents (households, firms and the government) and three types of markets (goods markets, labor markets and a bond market). We suppose that in each market one side of the market chooses the price and the other side of the market chooses the quantity. In goods markets, firms set prices and households decide how much to buy. In labor markets, households set wage rates and firms decide how much to hire. In the bond market, the government sets the nominal interest rate and households decide how many bonds to hold.

\subsection{Households}

There are $J$ households in the economy. Households supply differentiated types of labor, consume a variety of goods, and hold nominal government bonds.

Time is discrete and households have an infinite horizon. Each household seeks to maximize the expected discounted sum of period utility. The discount factor is $\beta \in(0,1)$. The period utility function is

$$
U\left(C_{j t}, L_{j t}\right)=\frac{C_{j t}^{1-\gamma}-1}{1-\gamma}-\varphi \frac{L_{j t}^{1+\psi}}{1+\psi}
$$

where

$$
C_{j t}=\left(\sum_{i=1}^{I} C_{i j t}^{\frac{\theta-1}{\theta}}\right)^{\frac{\theta}{\theta-1}} .
$$


Here $C_{j t}$ is composite consumption by household $j$ in period $t, L_{j t}$ is labor supply by household $j$ in period $t$, and $C_{i j t}$ is consumption of good $i$ by household $j$ in period $t$. The parameter $\gamma>0$ is the inverse of the intertemporal elasticity of substitution. The parameters $\varphi>0$ and $\psi \geq 0$ affect the disutility of supplying labor. There are $I$ different consumption goods and the parameter $\theta>1$ is the elasticity of substitution between those consumption goods. ${ }^{5}$

The flow budget constraint of household $j$ in period $t$ reads

$$
\sum_{i=1}^{I} P_{i t} C_{i j t}+B_{j t}=R_{t-1} B_{j t-1}+\left(1+\tau_{w}\right) W_{j t} L_{j t}+\frac{D_{t}}{J}-\frac{T_{t}}{J},
$$

where $P_{i t}$ is the price of good $i$ in period $t, B_{j t}$ are holdings of nominal government bonds by household $j$ between period $t$ and period $t+1, R_{t}$ is the nominal gross interest rate on those bond holdings, $W_{j t}$ is the nominal wage rate for labor supplied by household $j$ in period $t, \tau_{w}$ is a wage subsidy paid by the government, $\left(D_{t} / J\right)$ is a pro-rata share of nominal aggregate profits, and $\left(T_{t} / J\right)$ is a pro-rata share of nominal lump-sum taxes. We assume that all households have the same initial bond holdings $B_{j,-1}>0$. We also assume that bond holdings have to be positive in every period, $B_{j t}>0$. We have to make some assumption to rule out Ponzi schemes. We choose this particular assumption because it will allow us to express bond holdings in terms of log-deviations from the non-stochastic steady state. One can think of households as having an account. The account holds only nominal government bonds and the balance on the account has to be positive.

In every period, each household chooses a consumption vector, $\left(C_{1 j t}, \ldots, C_{I j t}\right)$, and a wage rate. Each household commits to supply any quantity of labor at that wage rate.

Each household takes as given: all prices of consumption goods, the nominal wage index defined below, the nominal interest rate, and all aggregate quantities.

\section{$2.2 \quad$ Firms}

There are $I$ firms in the economy. Firms supply differentiated consumption goods.

Firm $i$ supplies good $i$. The production function of firm $i$ is

$$
Y_{i t}=e^{a_{t}} e^{a_{i t}} L_{i t}^{\alpha},
$$

\footnotetext{
${ }^{5}$ The assumption of a constant elasticity of substitution between consumption goods is only for ease of exposition. One could use a general constant returns-to-scale consumption aggregator.
} 
where

$$
L_{i t}=\left(\sum_{j=1}^{J} L_{i j t}^{\frac{\eta-1}{\eta}}\right)^{\frac{\eta}{\eta-1}} .
$$

Here $Y_{i t}$ is output, $L_{i t}$ is composite labor input, $L_{i j t}$ is input of type $j$ labor, and $\left(e^{a_{t}} e^{a_{i t}}\right)$ is total factor productivity of firm $i$ in period $t$. Type $j$ labor is labor supplied by household $j$. There are $J$ different types of labor. The parameter $\eta>1$ is the elasticity of substitution between those types of labor. The parameter $\alpha \in(0,1]$ is the elasticity of output with respect to composite labor input. Total factor productivity has an aggregate component, $e^{a_{t}}$, and a firm-specific component, $e^{a_{i t}}$.

Nominal profit of firm $i$ in period $t$ equals

$$
\left(1+\tau_{p}\right) P_{i t} Y_{i t}-\sum_{j=1}^{J} W_{j t} L_{i j t},
$$

where $\tau_{p}$ is a production subsidy paid by the government.

In every period, each firm sets a price, $P_{i t}$, and chooses a labor mix, $\left(\hat{L}_{i 1 t}, \ldots, \hat{L}_{i(J-1) t}\right)$, where $\hat{L}_{i j t}=\left(L_{i j t} / L_{i t}\right)$ denotes firm $i$ 's relative input of type $j$ labor in period $t$. Each firm commits to supply any quantity of the good at that price. Each firm produces the quantity demanded with the chosen labor mix.

Each firm takes as given: all wage rates, the price index defined below, the nominal interest rate, all aggregate quantities, and total factor productivity.

\subsection{Government}

There is a monetary authority and a fiscal authority. The monetary authority sets the nominal interest rate according to the rule

$$
\frac{R_{t}}{R}=\left(\frac{R_{t-1}}{R}\right)^{\rho_{R}}\left[\left(\frac{\Pi_{t}}{\Pi}\right)^{\phi_{\pi}}\left(\frac{Y_{t}}{Y}\right)^{\phi_{y}}\right]^{1-\rho_{R}} e^{\varepsilon_{t}^{R}},
$$

where $\Pi_{t}=\left(P_{t} / P_{t-1}\right)$ is inflation, $Y_{t}$ is aggregate output defined as

$$
Y_{t}=\frac{\sum_{i=1}^{I} P_{i t} Y_{i t}}{P_{t}}
$$

and $\varepsilon_{t}^{R}$ is a monetary policy shock. The price index $P_{t}$ will be defined later. Here $R, \Pi$ and $Y$ denote the values of the nominal interest rate, inflation and aggregate output in the non-stochastic steady state. The policy parameters are assumed to satisfy $\rho_{R} \in[0,1), \phi_{\pi}>1$ and $\phi_{y} \geq 0$. 
The government budget constraint in period $t$ reads

$$
T_{t}+B_{t}=R_{t-1} B_{t-1}+\tau_{p}\left(\sum_{i=1}^{I} P_{i t} Y_{i t}\right)+\tau_{w}\left(\sum_{j=1}^{J} W_{j t} L_{j t}\right) .
$$

The government has to finance maturing nominal government bonds, the production subsidy and the wage subsidy. The government can collect lump-sum taxes or issue new government bonds.

We assume that the government sets the production subsidy, $\tau_{p}$, and the wage subsidy, $\tau_{w}$, so as to correct the distortions arising from firms' market power in the goods market and households' market power in the labor market. In particular, we assume that

$$
\tau_{p}=\frac{\tilde{\theta}}{\tilde{\theta}-1}-1
$$

where $\tilde{\theta}$ denotes the price elasticity of demand, and

$$
\tau_{w}=\frac{\tilde{\eta}}{\tilde{\eta}-1}-1
$$

where $\tilde{\eta}$ denotes the wage elasticity of labor demand. We make this assumption to abstract from the level distortions arising from monopolistic competition. ${ }^{6}$

\subsection{Shocks}

There are three types of shocks in the economy: aggregate technology shocks, firm-specific productivity shocks, and monetary policy shocks. We assume that the stochastic processes $\left\{a_{t}\right\},\left\{a_{1 t}\right\}$, $\left\{a_{2 t}\right\}, \ldots,\left\{a_{I t}\right\}$ and $\left\{\varepsilon_{t}^{R}\right\}$ are independent. Furthermore, we assume that $a_{t}$ follows a stationary Gaussian first-order autoregressive process with mean zero, each $a_{i t}$ follows a stationary Gaussian first-order autoregressive process with mean zero, and $\varepsilon_{t}^{R}$ follows a Gaussian white noise process. In the following, we denote the period $t$ innovation to $a_{t}$ and $a_{i t}$ by $\varepsilon_{t}^{A}$ and $\varepsilon_{i t}^{I}$, respectively.

When we aggregate decisions by individual firms, the term $\frac{1}{I} \sum_{i=1}^{I} \varepsilon_{i t}^{I}$ appears. This term is a random variable with mean zero and variance $\frac{1}{I} \operatorname{Var}\left(\varepsilon_{i t}^{I}\right)$. When we aggregate individual decisions, we neglect this term because the term has mean zero and a variance that can be made small by setting the number of firms $I$ equal to a large number. We work with a finite number of firms because a household with rational inattention cannot track a continuum of prices. ${ }^{7}$

\footnotetext{
${ }^{6}$ When households have perfect information, the price elasticity of demand $\tilde{\theta}$ equals the preference parameter $\theta$. When households have imperfect information, the price elasticity of demand $\tilde{\theta}$ may differ from the preference parameter $\theta$. Hence, the value of the production subsidy (10) may vary across information structures.

${ }^{7}$ Dixit and Stiglitz (1977) also assume that there is a finite number of firms and that firms take the price index
} 


\subsection{Notation}

In this subsection we introduce convenient notation. Throughout the paper, $C_{t}$ denotes aggregate composite consumption

$$
C_{t}=\sum_{j=1}^{J} C_{j t},
$$

and $L_{t}$ denotes aggregate composite labor input

$$
L_{t}=\sum_{i=1}^{I} L_{i t} .
$$

Furthermore, $\hat{P}_{i t}$ denotes the relative price of good $i$

$$
\hat{P}_{i t}=\frac{P_{i t}}{P_{t}},
$$

and $\hat{W}_{j t}$ denotes the relative wage rate for type $j$ labor

$$
\hat{W}_{j t}=\frac{W_{j t}}{W_{t}} .
$$

In addition, $\tilde{W}_{j t}$ denotes the real wage rate for type $j$ labor

$$
\tilde{W}_{j t}=\frac{W_{j t}}{P_{t}}
$$

and $\tilde{W}_{t}$ denotes the real wage index

$$
\tilde{W}_{t}=\frac{W_{t}}{P_{t}}
$$

In each section we will specify the definition of $P_{t}$ and $W_{t}$.

\section{Derivation of the firms' objective}

In this section we derive a log-quadratic approximation to expected profits. We use this expression for expected profits below when we assume that decision-makers in firms choose the allocation of their attention so as to maximize expected profits. To derive this expression, we proceed in four steps: (i) we make a guess concerning the demand function for good $i$, (ii) we derive the profit function of firm $i$, (iii) we make an assumption about how decision-makers in firms value profit as given. Moreover, it seems a good description of the U.S. economy that there is a finite number of firms producing consumption goods and that firms take the consumer price index (CPI) as given. 
in different states of the world, and (iv) we compute a log-quadratic approximation to expected profits around the non-stochastic steady state. ${ }^{8}$ The result is summarized in Proposition 1.

First, we make a guess concerning the demand function. We guess that the demand function for good $i$ has the form

$$
C_{i t}=\vartheta\left(\frac{P_{i t}}{P_{t}}\right)^{-\tilde{\theta}} C_{t},
$$

where $C_{t}$ is aggregate composite consumption and $P_{t}$ is a price index satisfying the next equation for some function $d$ that is symmetric, homogenous of degree one and continuously differentiable

$$
P_{t}=d\left(P_{1 t}, \ldots, P_{I t}\right)
$$

Here the price elasticity of demand $\tilde{\theta}>1$ is an undetermined coefficient and the constant $\vartheta$ equals

$$
\vartheta=\hat{P}_{i}^{-(\theta-\tilde{\theta})},
$$

where $\hat{P}_{i}$ is the relative price of good $i$ in the non-stochastic steady state. In Sections 6-8 we solve the model for alternative assumptions about information flows and we verify that this guess concerning the demand function is correct. ${ }^{9}$

Second, we derive the profit function. Substituting the production function (4)-(5), $Y_{i t}=C_{i t}$ and the demand function (18) into the expression for profit (6) yields

$$
\left(1+\tau_{p}\right) P_{i t} \vartheta\left(\frac{P_{i t}}{P_{t}}\right)^{-\tilde{\theta}} C_{t}-\left[\frac{\vartheta\left(\frac{P_{i t}}{P_{t}}\right)^{-\tilde{\theta}} C_{t}}{e^{a_{t}} e^{a_{i t}}}\right]^{\frac{1}{\alpha}}\left[\sum_{j=1}^{J-1} W_{j t} \hat{L}_{i j t}+W_{J t}\left(1-\sum_{j=1}^{J-1} \hat{L}_{i j t}^{\frac{\eta-1}{\eta}}\right)^{\frac{\eta}{\eta-1}}\right] .
$$

Profit equals revenue minus cost. Here cost equals the wage bill and the wage bill is expressed as the product of composite labor input and the wage bill per unit of composite labor input. Note that profit of firm $i$ in period $t$ depends on the price set by the decision-maker in the firm, $P_{i t}$, the labor mix chosen by the decision-maker in the firm, $\left(\hat{L}_{i 1 t}, \ldots, \hat{L}_{i(J-1) t}\right)$, and variables that the decision-maker in the firm takes as given.

\footnotetext{
${ }^{8}$ The non-stochastic steady state of the economy is characterized in Appendix A. The inflation rate in the nonstochastic steady state is not uniquely determined. For ease of exposition, we select the zero inflation steady state (i.e., $\Pi=1$ ). The value of inflation in the non-stochastic steady state has no effect on real variables in both the non-stochastic version and the stochastic version of the economy.

${ }^{9}$ For example, when households have perfect information then $P_{t}=\left(\sum_{i=1}^{I} P_{i t}^{1-\theta}\right)^{\frac{1}{1-\theta}}$ and $\tilde{\theta}=\theta$.
} 
Third, we make an assumption about how decision-makers in firms value profit in different states of the world. Since the economy described in Section 2 is an incomplete-markets economy with multiple owners of a firm, it is unclear how firms value profit in different states of the world. Therefore, we assume a general stochastic discount factor. We assume that in period -1 decisionmakers in firms value nominal profit in period $t$ using the following stochastic discount factor

$$
Q_{-1, t}=\beta^{t} \Lambda\left(C_{1 t}, \ldots, C_{J t}\right) \frac{1}{P_{t}},
$$

where $P_{t}$ is the price index appearing in the demand function (18) and $\Lambda$ is some twice continuously differentiable function with the property that the value of this function at the non-stochastic steady state equals the marginal utility of consumption in the non-stochastic steady state ${ }^{10}$

$$
\Lambda\left(C_{1}, \ldots, C_{J}\right)=C_{j}^{-\gamma}
$$

Then, the expected discounted sum of profits in period -1 equals

$$
E_{i,-1}\left[\sum_{t=0}^{\infty} \beta^{t} F\left(\hat{P}_{i t}, \hat{L}_{i 1 t}, \ldots, \hat{L}_{i(J-1) t}, a_{t}, a_{i t}, C_{1 t}, \ldots, C_{J t}, \tilde{W}_{1 t}, \ldots, \tilde{W}_{J t}\right)\right],
$$

where $E_{i,-1}$ is the expectation operator conditioned on the information of the decision-maker in firm $i$ in period -1 and the function $F$ is given by

$$
\begin{aligned}
& F\left(\hat{P}_{i t}, \hat{L}_{i 1 t}, \ldots, \hat{L}_{i(J-1) t}, a_{t}, a_{i t}, C_{1 t}, \ldots, C_{J t}, \tilde{W}_{1 t}, \ldots, \tilde{W}_{J t}\right) \\
= & \Lambda\left(C_{1 t}, \ldots, C_{J t}\right)\left(1+\tau_{p}\right) \vartheta \hat{P}_{i t}^{1-\tilde{\theta}}\left(\sum_{j=1}^{J} C_{j t}\right) \\
& -\Lambda\left(C_{1 t}, \ldots, C_{J t}\right)\left[\frac{\vartheta \hat{P}_{i t}^{-\tilde{\theta}}\left(\sum_{j=1}^{J} C_{j t}\right)}{e^{a_{t}} e^{a_{i t}}}\right]^{\frac{1}{\alpha}}\left[\sum_{j=1}^{J-1} \tilde{W}_{j t} \hat{L}_{i j t}+\tilde{W}_{J t}\left(1-\sum_{j=1}^{J-1} \hat{L}_{i j t}^{\frac{\eta-1}{\eta}}\right)^{\frac{\eta}{\eta-1}}\right] .
\end{aligned}
$$

We call $F$ the real profit function.

Fourth, we express the real profit function in terms of log-deviations from the non-stochastic steady state and we compute a quadratic approximation to this function. In the following, variables

\footnotetext{
${ }^{10}$ For example, the stochastic discount factor could be a weighted average of the marginal utilities of the different households (i.e., $\Lambda\left(C_{1 t}, \ldots, C_{J t}\right)=\sum_{j=1}^{J} \Lambda_{j} C_{j t}^{-\gamma}$ with $\Lambda_{j} \geq 0$ and $\left.\sum_{j=1}^{J} \Lambda_{j}=1\right)$. Equation (23) would be satisfied because all households have the same marginal utility in the non-stochastic steady state. See Appendix A.
} 
without time subscript denote values in the non-stochastic steady state and small variables denote log-deviations from the non-stochastic steady state. For example, $c_{j t}=\ln \left(C_{j t} / C_{j}\right)$. Expressing the real profit function $F$ in terms of log-deviations from the non-stochastic steady state and using equation (10), equation (20) and the steady state relationships (115), (116), (118), $Y_{i}=L_{i}^{\alpha}$ and $Y_{i}=\hat{P}_{i}^{-\theta} C$ yields the following real profit function

$$
\begin{aligned}
& f\left(\hat{p}_{i t}, \hat{l}_{i 1 t}, \ldots, \hat{l}_{i(J-1) t}, a_{t}, a_{i t}, c_{1 t}, \ldots, c_{J t}, \tilde{w}_{1 t}, \ldots, \tilde{w}_{J t}\right) \\
= & \Lambda\left(C_{1} e^{c_{1 t}}, \ldots, C_{J} e^{c_{J t}}\right) \frac{\tilde{\theta}}{\tilde{\theta}-1} \frac{1}{\alpha} \tilde{W} L_{i} \frac{1}{J} \sum_{j=1}^{J} e^{(1-\tilde{\theta}) \hat{p}_{i t}+c_{j t}} \\
& -\Lambda\left(C_{1} e^{c_{1 t}}, \ldots, C_{J} e^{c_{J t}}\right) \tilde{W} L_{i} e^{-\frac{\tilde{\theta}}{\alpha} \hat{p}_{i t}-\frac{1}{\alpha}\left(a_{t}+a_{i t}\right)}\left(\frac{1}{J} \sum_{j=1}^{J} e^{c_{j t}}\right)^{\frac{1}{\alpha}} \\
& \frac{1}{J}\left[\sum_{j=1}^{J-1} e^{\tilde{w}_{j t}+\hat{l}_{i j t}}+e^{\tilde{w}_{J t}}\left(J-\sum_{j=1}^{J-1} e^{\frac{\eta-1}{\eta} \hat{l}_{i j t}}\right)^{\frac{\eta}{\eta-1}}\right]
\end{aligned}
$$

A second-order Taylor approximation to the real profit function $f$ yields the result summarized in Proposition 1.

Proposition 1 (Expected discounted sum of profits) Let $f$ denote the real profit function given by equation (26). Let $\tilde{f}$ denote the second-order Taylor approximation to $f$ at the non-stochastic steady state. Let $E_{i,-1}$ denote the expectation operator conditioned on the information of the decisionmaker in firm $i$ in period -1 . Let $x_{t}$, $z_{t}$ and $v_{t}$ denote the following vectors

$$
\begin{aligned}
& x_{t}^{\prime}=\left(\begin{array}{llll}
\hat{p}_{i t} & \hat{l}_{i 1 t} & \cdots & \hat{l}_{i(J-1) t}
\end{array}\right), \\
& z_{t}^{\prime}=\left(\begin{array}{llllllll}
a_{t} & a_{i t} & c_{1 t} & \cdots & c_{J t} & \tilde{w}_{1 t} & \cdots & \tilde{w}_{J t}
\end{array}\right), \\
& v_{t}^{\prime}=\left(\begin{array}{lll}
x_{t}^{\prime} & z_{t}^{\prime} & 1
\end{array}\right) \text {, }
\end{aligned}
$$

and let $v_{m, t}$ and $v_{n, t}$ denote the mth and nth element of $v_{t}$. Suppose that there exist two constants $\delta<(1 / \beta)$ and $A \in \mathbb{R}$ such that, for all $m$ and $n$ and for each period $t \geq 0$,

$$
E_{i,-1}\left|v_{m, t} v_{n, t}\right|<\delta^{t} A
$$

Then the expected discounted sum of profit losses in the case of suboptimal decisions equals

$$
E_{i,-1}\left[\sum_{t=0}^{\infty} \beta^{t} \tilde{f}\left(x_{t}, z_{t}\right)\right]-E_{i,-1}\left[\sum_{t=0}^{\infty} \beta^{t} \tilde{f}\left(x_{t}^{*}, z_{t}\right)\right]=\sum_{t=0}^{\infty} \beta^{t} E_{i,-1}\left[\frac{1}{2}\left(x_{t}-x_{t}^{*}\right)^{\prime} H\left(x_{t}-x_{t}^{*}\right)\right],
$$


where the matrix $H$ is given by

$$
H=-C_{j}^{-\gamma} \tilde{W} L_{i}\left[\begin{array}{ccccc}
\frac{\tilde{\theta}}{\alpha}\left(1+\frac{1-\alpha}{\alpha} \tilde{\theta}\right) & 0 & \cdots & \cdots & 0 \\
0 & \frac{2}{\eta J} & \frac{1}{\eta J} & \cdots & \frac{1}{\eta J} \\
\vdots & \frac{1}{\eta J} & \ddots & \ddots & \vdots \\
\vdots & \vdots & \ddots & \ddots & \frac{1}{\eta J} \\
0 & \frac{1}{\eta J} & \cdots & \frac{1}{\eta J} & \frac{2}{\eta J}
\end{array}\right],
$$

and the vector $x_{t}^{*}$ is given by

$$
\hat{p}_{i t}^{*}=\frac{\frac{1-\alpha}{\alpha}}{1+\frac{1-\alpha}{\alpha} \tilde{\theta}}\left(\frac{1}{J} \sum_{j=1}^{J} c_{j t}\right)+\frac{1}{1+\frac{1-\alpha}{\alpha} \tilde{\theta}}\left(\frac{1}{J} \sum_{j=1}^{J} \tilde{w}_{j t}\right)-\frac{\frac{1}{\alpha}}{1+\frac{1-\alpha}{\alpha} \tilde{\theta}}\left(a_{t}+a_{i t}\right),
$$

and

$$
\hat{l}_{i j t}^{*}=-\eta\left(\tilde{w}_{j t}-\frac{1}{J} \sum_{j=1}^{J} \tilde{w}_{j t}\right) .
$$

Proof. See Appendix B in Maćkowiak and Wiederholt (2010).

After the log-quadratic approximation to the real profit function, the profit-maximizing price in period $t$ is given by equation (33) and the profit-maximizing labor mix in period $t$ is given by equation (34). Furthermore, the loss in profit in period $t$ in the case of suboptimal decisions is given by the quadratic form in expression (31). The upper-left element of the matrix $H$ determines the loss in profit in the case of a suboptimal price. The lower-right block of the matrix $H$ determines the loss in profit in the case of a suboptimal labor mix. The diagonal elements of $H$ determine the profit loss in the case of a deviation in a single variable, while the off-diagonal elements of $H$ determine how a deviation in one variable affects the profit loss due to a deviation in another variable. The profit loss in the case of a suboptimal price is increasing in the price elasticity of demand, $\tilde{\theta}$, and increasing in the degree of decreasing returns-to-scale, $(1 / \alpha)$. The profit loss in the case of a suboptimal labor mix is decreasing in the elasticity of substitution between types of labor, $\eta$, and depends on the number of types of labor, $J$. Finally, condition (30) ensures that in the expressions for the expected discounted sum of profits on the left-hand side of equation (31) one can change the order of integration and summation and the infinite sum converges.

Note that the profit-maximizing decision vector (33)-(34) does not depend at all on the function $\Lambda$ appearing in the stochastic discount factor (22). This is because the profit-maximizing price and 
labor mix are the solution to a static maximization problem. Furthermore, the expected discounted sum of profit losses (31) depends only on the value of the function $\Lambda$ at the non-stochastic steady state. The reason is the log-quadratic approximation to the real profit function around the nonstochastic steady state.

Proposition 1 gives an expression for expected profit losses in the case of suboptimal decisions for the economy presented in Section 2 when the demand function is given by equation (18) and the stochastic discount factor is given by equation (22). From this expression one can already see to some extent how the decision-maker in a firm who cannot attend perfectly to all available information will allocate his or her attention. For example, the attention devoted to the price setting decision will depend on the loss in profit in the case of a deviation of the price from the profit-maximizing price. Formally, the attention devoted to the price setting decision will depend on the upper-left element of the matrix $H$. Furthermore, for the decision-maker in a firm it is particularly important to track those changes in the environment that in expectation cause most of the fluctuations in the profit-maximizing decisions. As one can see from equations (33)-(34), which changes in the environment in expectation cause most of the fluctuations in the profit-maximizing decisions depends on the calibration of the exogenous processes, the technology parameters $\alpha$ and $\eta$, and the behavior of other agents in the economy. Namely, the price setting behavior of other firms and the consumption and wage setting behavior of households will affect the optimal allocation of attention by the decision-maker in a firm.

\section{Derivation of the households' objective}

In this section we derive a log-quadratic approximation to expected utility. We use this expression for expected utility below when we assume that households choose the allocation of attention so as to maximize expected utility. To derive this expression, we proceed in three steps: (i) we make a guess concerning the demand function for type $j$ labor, (ii) we substitute the labor demand function, the flow budget constraint, and the consumption aggregator into the period utility function to obtain a period utility function that incorporates these constraints, and (iii) we compute a log-quadratic approximation to expected utility around the non-stochastic steady state. The result is summarized in Proposition 2. 
First, we make a guess concerning the labor demand function. We guess that the demand function for type $j$ labor has the form

$$
L_{j t}=\zeta\left(\frac{W_{j t}}{W_{t}}\right)^{-\tilde{\eta}} L_{t}
$$

where $L_{t}$ is aggregate composite labor input and $W_{t}$ is a wage index satisfying the next equation for some function $h$ that is symmetric, homogenous of degree one and continuously differentiable

$$
W_{t}=h\left(W_{1 t}, \ldots, W_{J t}\right)
$$

Here the wage elasticity of labor demand $\tilde{\eta}>1$ is an undetermined coefficient and the constant $\zeta$ equals

$$
\zeta=\hat{W}_{j}^{-(\eta-\tilde{\eta})} .
$$

In Sections 6-8 we solve the model for alternative assumptions about information flows and we verify that this guess concerning the labor demand function is correct. ${ }^{11}$

Second, we substitute the labor demand function, the flow budget constraint, and the consumption aggregator into the period utility function to obtain a period utility function that incorporates these constraints. Rearranging the flow budget constraint (3) yields

$$
C_{j t}=\frac{R_{t-1} B_{j t-1}-B_{j t}+\left(1+\tau_{w}\right) W_{j t} L_{j t}+\frac{D_{t}}{J}-\frac{T_{t}}{J}}{\sum_{i=1}^{I} P_{i t} \hat{C}_{i j t}}
$$

where $\hat{C}_{i j t}=\left(C_{i j t} / C_{j t}\right)$ is relative consumption of good $i$ and the denominator on the right-hand side is consumption expenditure per unit of composite consumption. Dividing the numerator and the denominator on the right-hand side by some price index $P_{t}$ yields

$$
C_{j t}=\frac{\frac{R_{t-1}}{\Pi_{t}} \tilde{B}_{j t-1}-\tilde{B}_{j t}+\left(1+\tau_{w}\right) \tilde{W}_{j t} L_{j t}+\frac{\tilde{D}_{t}}{J}-\frac{\tilde{T}_{t}}{J}}{\sum_{i=1}^{I} \hat{P}_{i t} \hat{C}_{i j t}},
$$

where $\tilde{B}_{j t}=\left(B_{j t} / P_{t}\right)$ are real bond holdings by the household, $\Pi_{t}=\left(P_{t} / P_{t-1}\right)$ is inflation, $\tilde{D}_{t}=\left(D_{t} / P_{t}\right)$ are real aggregate profits, and $\tilde{T}_{t}=\left(T_{t} / P_{t}\right)$ are real lump-sum taxes. Furthermore, rearranging the consumption aggregator $(2)$ yields

$$
1=\sum_{i=1}^{I} \hat{C}_{i j t}^{\frac{\theta-1}{\theta}} .
$$

\footnotetext{
${ }^{11}$ For example, when firms have perfect information then $W_{t}=\left(\sum_{j=1}^{J} W_{j t}^{1-\eta}\right)^{\frac{1}{1-\eta}}$ and $\tilde{\eta}=\eta$.
} 
Substituting the labor demand function (35), the flow budget constraint (38), and the consumption aggregator (39) into the period utility function (1) yields a period utility function that incorporates these constraints:

$$
\begin{aligned}
& \frac{1}{1-\gamma}\left(\frac{\frac{R_{t-1}}{\Pi_{t}} \tilde{B}_{j t-1}-\tilde{B}_{j t}+\left(1+\tau_{w}\right) \tilde{W}_{j t} \zeta\left(\frac{\tilde{W}_{j t}}{\tilde{W}_{t}}\right)^{-\tilde{\eta}} L_{t}+\frac{\tilde{D}_{t}}{J}-\frac{\tilde{T}_{t}}{J}}{\sum_{i=1}^{I-1} \hat{P}_{i t} \hat{C}_{i j t}+\hat{P}_{I t}\left(1-\sum_{i=1}^{I-1} \hat{C}_{i j t}^{\frac{\theta-1}{\theta}}\right)^{\frac{\theta}{\theta-1}}}\right)^{1-\gamma} \\
& -\frac{1}{1-\gamma}-\frac{\varphi}{1+\psi}\left[\zeta\left(\frac{\tilde{W}_{j t}}{\tilde{W}_{t}}\right)^{-\tilde{\eta}} L_{t}\right]^{1+\psi} .
\end{aligned}
$$

Third, we express the period utility function (40) in terms of log-deviations from the nonstochastic steady state and we compute a quadratic approximation to the expected discounted sum of period utility around the non-stochastic steady state. Expressing the period utility function (40) in terms of log-deviations from the non-stochastic steady state and using equation (11), equation (37) and the steady state relationships (112)-(114), (117) and $L_{j}=\hat{W}_{j}^{-\eta} L$ yields the following period utility function

$$
\begin{aligned}
& \frac{C_{j}^{1-\gamma}}{1-\gamma}\left(\frac{\frac{\omega_{B}}{\beta} e^{r_{t-1}-\pi_{t}+\tilde{b}_{j t-1}}-\omega_{B} e^{\tilde{b}_{j t}}+\frac{\tilde{\eta}}{\tilde{\eta}-1} \omega_{W} e^{(1-\tilde{\eta}) \tilde{w}_{j t}+\tilde{\eta} \tilde{w}_{t}+l_{t}}+\omega_{D} e^{\tilde{d}_{t}}-\omega_{T} e^{\tilde{t}_{t}}}{\frac{1}{I} \sum_{i=1}^{I-1} e^{\hat{p}_{i t}+\hat{c}_{i j t}}+\frac{1}{I} e^{\hat{p}_{I t}}\left(I-\sum_{i=1}^{I-1} e^{\frac{\theta-1}{\theta} \hat{c}_{i j t}}\right)^{\frac{\theta}{\theta-1}}}\right)^{1-\gamma} \\
& -\frac{1}{1-\gamma}-\frac{C_{j}^{1-\gamma}}{1+\psi} \omega_{W} e^{-\tilde{\eta}(1+\psi)\left(\tilde{w}_{j t}-\tilde{w}_{t}\right)+(1+\psi) l_{t}}
\end{aligned}
$$

where $\omega_{B}, \omega_{W}, \omega_{D}$ and $\omega_{T}$ denote the following steady state ratios

$$
\left(\begin{array}{llll}
\omega_{B} & \omega_{W} & \omega_{D} & \omega_{T}
\end{array}\right)=\left(\begin{array}{cccc}
\tilde{B}_{j} & \frac{\tilde{W}_{j} L_{j}}{C_{j}} & \frac{\tilde{D}}{C_{j}} & \frac{\tilde{T}}{C_{j}}
\end{array}\right) .
$$

A second-order Taylor approximation to the expected discounted sum of period utility yields the result summarized in Proposition 2.

Proposition 2 (Expected discounted sum of period utility) Let $g$ denote the functional that is obtained by multiplying the period utility function (41) by $\beta^{t}$ and summing over all $t$ from zero to infinity. Let $\tilde{g}$ denote the second-order Taylor approximation to $g$ at the non-stochastic steady state. 
Let $E_{j,-1}$ denote the expectation operator conditioned on information of household $j$ in period -1 . Let $x_{t}, z_{t}$ and $v_{t}$ denote the following vectors

$$
\begin{aligned}
& x_{t}^{\prime}=\left(\begin{array}{lllll}
\tilde{b}_{j t} & \tilde{w}_{j t} & \hat{c}_{1 j t} & \cdots & \hat{c}_{I-1 j t}
\end{array}\right), \\
& z_{t}^{\prime}=\left(\begin{array}{lllllllll}
r_{t-1} & \pi_{t} & \tilde{w}_{t} & l_{t} & \tilde{d}_{t} & \tilde{t}_{t} & \hat{p}_{1 t} & \cdots & \hat{p}_{I t}
\end{array}\right), \\
& v_{t}^{\prime}=\left(\begin{array}{lll}
x_{t}^{\prime} & z_{t}^{\prime} & 1
\end{array}\right),
\end{aligned}
$$

and let $v_{m, t}$ and $v_{n, t}$ denote the $m$ th and $n$th element of $v_{t}$. Suppose that

$$
E_{j,-1}\left[\tilde{b}_{j,-1}^{2}\right]<\infty,
$$

and for all $n$,

$$
E_{j,-1}\left|\tilde{b}_{j,-1} v_{n, 0}\right|<\infty .
$$

Suppose also that there exist two constants $\delta<(1 / \beta)$ and $A \in \mathbb{R}$ such that, for all $m$ and $n$, for each period $t \geq 0$, and for $\tau=0,1$,

$$
E_{j,-1}\left|v_{m, t} v_{n, t+\tau}\right|<\delta^{t} A .
$$

Then the expected discounted sum of utility losses in the case of suboptimal decisions equals

$$
\begin{aligned}
& E_{j,-1}\left[\tilde{g}\left(\tilde{b}_{j,-1}, x_{0}, z_{0}, x_{1}, z_{1}, \ldots\right)\right]-E_{j,-1}\left[\tilde{g}\left(\tilde{b}_{j,-1}, x_{0}^{*}, z_{0}, x_{1}^{*}, z_{1}, \ldots\right)\right] \\
= & \sum_{t=0}^{\infty} \beta^{t} E_{j,-1}\left[\frac{1}{2}\left(x_{t}-x_{t}^{*}\right)^{\prime} H_{0}\left(x_{t}-x_{t}^{*}\right)+\left(x_{t}-x_{t}^{*}\right)^{\prime} H_{1}\left(x_{t+1}-x_{t+1}^{*}\right)\right] .
\end{aligned}
$$

Here the matrix $H_{0}$ equals

$$
H_{0}=-C_{j}^{1-\gamma}\left[\begin{array}{ccccc}
\gamma \omega_{B}^{2}\left(1+\frac{1}{\beta}\right) & \gamma \omega_{B} \tilde{\eta} \omega_{W} & 0 & \cdots & 0 \\
\gamma \omega_{B} \tilde{\eta} \omega_{W} & \tilde{\eta} \omega_{W}\left(\gamma \tilde{\eta} \omega_{W}+1+\psi \tilde{\eta}\right) & 0 & \cdots & 0 \\
0 & 0 & \frac{2}{\theta I} & \cdots & \frac{1}{\theta I} \\
\vdots & \vdots & \vdots & \ddots & \vdots \\
0 & 0 & \frac{1}{\theta I} & \cdots & \frac{2}{\theta I}
\end{array}\right],
$$

the matrix $H_{1}$ equals

$$
H_{1}=C_{j}^{1-\gamma}\left[\begin{array}{ccccc}
\gamma \omega_{B}^{2} & \gamma \omega_{B} \tilde{\eta} \omega_{W} & 0 & \cdots & 0 \\
0 & 0 & 0 & \cdots & 0 \\
0 & 0 & 0 & \cdots & 0 \\
\vdots & \vdots & \vdots & \ddots & \vdots \\
0 & 0 & 0 & \cdots & 0
\end{array}\right]
$$


and the stochastic process $\left\{x_{t}^{*}\right\}_{t=0}^{\infty}$ is defined by the following three requirements: (i) $\tilde{b}_{j,-1}^{*}=\tilde{b}_{j,-1}$, (ii) in each period $t \geq 0$, the vector $x_{t}^{*}$ satisfies

$$
\begin{aligned}
c_{j t}^{*} & =E_{t}\left[-\frac{1}{\gamma}\left(r_{t}-\pi_{t+1}-\frac{1}{I} \sum_{i=1}^{I}\left(\hat{p}_{i t+1}-\hat{p}_{i t}\right)\right)+c_{j t+1}^{*}\right], \\
\tilde{w}_{j t}^{*} & =\frac{\gamma}{1+\tilde{\eta} \psi} c_{j t}^{*}+\frac{\psi}{1+\tilde{\eta} \psi}\left(\tilde{\eta} \tilde{w}_{t}+l_{t}\right)+\frac{1}{1+\tilde{\eta} \psi}\left(\frac{1}{I} \sum_{i=1}^{I} \hat{p}_{i t}\right), \\
\hat{c}_{i j t}^{*} & =-\theta\left(\hat{p}_{i t}-\frac{1}{I} \sum_{i=1}^{I} \hat{p}_{i t}\right),
\end{aligned}
$$

where the variable $c_{j t}^{*}$ is defined by

$c_{j t}^{*}=\frac{\omega_{B}}{\beta}\left(r_{t-1}-\pi_{t}+\tilde{b}_{j t-1}^{*}\right)-\omega_{B} \tilde{b}_{j t}^{*}+\frac{\tilde{\eta}}{\tilde{\eta}-1} \omega_{W}\left[(1-\tilde{\eta}) \tilde{w}_{j t}^{*}+\tilde{\eta} \tilde{w}_{t}+l_{t}\right]+\omega_{D} \tilde{d}_{t}-\omega_{T} \tilde{t}_{t}-\left(\frac{1}{I} \sum_{i=1}^{I} \hat{p}_{i t}\right)$,

and $E_{t}$ denotes the expectation operator conditioned on the entire history of the economy up to and including period $t$, and (iii) the vector $v_{t}$ with $x_{t}=x_{t}^{*}$ satisfies conditions (46)-(48).

Proof. See Appendix C in Maćkowiak and Wiederholt (2010).

After the log-quadratic approximation to the expected discounted sum of period utility, stochastic processes for real bond holdings, the real wage rate, and the consumption mix satisfying conditions (46)-(48) can be ranked using equation (49). Equations (52)-(55) characterize the decisions that the household would take if the household had perfect information in each period $t \geq 0$. After the log-quadratic approximation to expected utility, the optimal decisions under perfect information are given by the usual log-linear first-order conditions. Furthermore, equation (49) gives the loss in expected utility in the case of deviations of the actual decisions from the optimal decisions under perfect information. The upper-left blocks of the matrices $H_{0}$ and $H_{1}$ determine the loss in expected utility in the case of suboptimal real bond holdings and suboptimal real wage rates. According to the $(1,1)$ element of the matrix $H_{0}$, a single deviation of real bond holdings from optimal real bond holdings causes a larger utility loss the larger $\gamma, \omega_{B}$, and $(1 / \beta)=(R / \Pi)$. According to the $(2,2)$ element of the matrix $H_{0}$, a single deviation of the real wage rate from the optimal real wage rate causes a larger utility loss the larger $\gamma, \psi, \tilde{\eta}$, and $\omega_{W}$. In addition, the off-diagonal elements of $H_{0}$ show that a wage deviation in period $t$ affects the utility cost of a bond deviation in period $t$, and the first row of $H_{1}$ shows that a bond deviation in period $t$ affects the 
utility cost of a bond deviation in period $t+1$ and the utility cost of a wage deviation in period $t+1$. The lower-right block of the matrix $H_{0}$ determines the loss in expected utility in the case of a suboptimal consumption mix. The loss in expected utility in the case of a suboptimal consumption mix is decreasing in the elasticity of substitution between consumption goods, $\theta$, and depends on the number of consumption goods, I. Finally, conditions (46)-(48) ensure that in the expressions for the expected discounted sum of period utility on the left-hand side of equation (49) one can change the order of integration and summation and all infinite sums converge.

Proposition 2 gives an expression for the expected discounted sum of utility losses in the case of deviations of the actual decisions from the optimal decisions under perfect information for the economy presented in Section 2 when the labor demand function is given by equation (35). Proposition 2 is important because inattention leads to deviations of the actual decisions from the decisions that the household would take under perfect information. To choose the optimal allocation of attention, the household has to compare the cost in terms of expected utility of different types of deviations from the optimal decisions under perfect information. From Proposition 2 one can already see to some extent how parameters affect the optimal allocation of attention by a household. For example, consider the role of $\gamma$. Increasing $\gamma$ raises the utility loss in the case of a given deviation of real bond holdings from optimal real bond holdings. At the same time, increasing $\gamma$ lowers the response of optimal real bond holdings to the real interest rate. The relative strength of these two effects determines whether for a household with a higher $\gamma$ it is more or less important to be aware of movements in the real interest rate.

\section{Aggregation}

In this section we describe issues related to aggregation. In the following, we work with loglinearized equations for aggregate variables. Log-linearizing the equations for aggregate output (8), aggregate composite consumption (12), and aggregate composite labor input (13) yields

$$
\begin{gathered}
y_{t}=\frac{1}{I} \sum_{i=1}^{I}\left(\hat{p}_{i t}+y_{i t}\right), \\
c_{t}=\frac{1}{J} \sum_{j=1}^{J} c_{j t},
\end{gathered}
$$


and

$$
l_{t}=\frac{1}{I} \sum_{i=1}^{I} l_{i t} .
$$

Log-linearizing the equations for the price index (19) and the wage index (36) yields

$$
0=\sum_{i=1}^{I} \hat{p}_{i t},
$$

and

$$
0=\sum_{j=1}^{J} \hat{w}_{j t} .
$$

The last two equations can be stated as

$$
p_{t}=\frac{1}{I} \sum_{i=1}^{I} p_{i t},
$$

and

$$
w_{t}=\frac{1}{J} \sum_{j=1}^{J} w_{j t} .
$$

Furthermore, we work with log-linearized equations when we aggregate the demand for a particular consumption good or for a particular type of labor. Formally,

$$
c_{i t}=\frac{1}{J} \sum_{j=1}^{J} c_{i j t},
$$

and

$$
l_{j t}=\frac{1}{I} \sum_{i=1}^{I} l_{i j t} .
$$

Note that the production function (4) and the Taylor rule (7) are already log-linear:

$$
y_{i t}=a_{t}+a_{i t}+\alpha l_{i t}
$$

and

$$
r_{t}=\rho_{R} r_{t-1}+\left(1-\rho_{R}\right)\left(\phi_{\pi} \pi_{t}+\phi_{y} y_{t}\right)+\varepsilon_{t}^{R}
$$

\section{Solution under perfect information}

In this section we present the solution of the model under perfect information as a benchmark.

We define the equilibrium of the model under perfect information as follows. In each period $t$, all 
agents know the entire history of the economy up to and including period $t$. Firms choose the profitmaximizing price and labor mix, households choose the utility-maximizing consumption vector and wage rate, and the government sets the nominal interest rate according to the Taylor rule, sets the subsidies according to equations (10)-(11) and follows a Ricardian fiscal policy. Finally, aggregate variables are given by their respective equations and households have rational expectations.

The following proposition characterizes real variables at the solution of the model under perfect information after the log-quadratic approximation to the real profit function (see Section 3), the log-quadratic approximation to the expected discounted sum of period utility (see Section 4), and the log-linearization of the equations for the aggregate variables (see Section 5).

Proposition 3 (Solution of the model under perfect information) A solution to the system of equations (33)-(34), (52)-(55), (56)-(66) and $y_{i t}=c_{i t}$ with the same initial bond holdings for each household and a non-explosive bond sequence for each household (i.e., $\lim _{s \rightarrow \infty} E_{t}\left[\beta^{s}\left(\tilde{b}_{j, t+s}-\tilde{b}_{j, t+s-1}\right)\right]=0$ ) satisfies

$$
\begin{aligned}
y_{t} & =c_{t}=\frac{1+\psi}{1-\alpha+\alpha \gamma+\psi} a_{t}, \\
l_{t} & =\frac{1-\gamma}{1-\alpha+\alpha \gamma+\psi} a_{t}, \\
\tilde{w}_{t} & =\frac{\gamma+\psi}{1-\alpha+\alpha \gamma+\psi} a_{t}, \\
r_{t}-E_{t}\left[\pi_{t+1}\right] & =\gamma \frac{1+\psi}{1-\alpha+\alpha \gamma+\psi} E_{t}\left[a_{t+1}-a_{t}\right],
\end{aligned}
$$

and

$$
\begin{aligned}
\hat{c}_{i j t} & =-\theta \hat{p}_{i t}, \\
\hat{p}_{i t} & =-\frac{\frac{1}{\alpha}}{1+\frac{1-\alpha}{\alpha} \theta} a_{i t}, \\
\hat{l}_{i j t} & =-\eta \hat{w}_{j t}, \\
\hat{w}_{j t} & =0 .
\end{aligned}
$$

Proof. See Appendix D in Maćkowiak and Wiederholt (2010).

Under perfect information aggregate output, aggregate consumption, aggregate labor input, the real wage index, and the real interest rate are determined by aggregate technology. Furthermore, relative consumption of good $i$ by household $j$ is determined by firm-specific productivity. Finally, 
firm $i$ 's relative input of type $j$ labor is constant. Note that in this model under perfect information monetary policy has no effect on real variables. Monetary policy does affect nominal variables. The nominal interest rate and inflation follow from the Taylor rule (66) and the real interest rate (70). Since $\left(1-\rho_{R}\right) \phi_{\pi}>0$ and $\left(1-\rho_{R}\right) \phi_{\pi}+\rho_{R}>1$, the equilibrium paths of the nominal interest rate and inflation are locally determinate. ${ }^{12}$

\section{Rational inattention by firms}

In this section we solve the model with rational inattention by decision-makers in firms and perfect information by households. We maintain the assumption that households have perfect information for the moment to isolate the implications of rational inattention by decision-makers in firms.

\subsection{The attention problem of the decision-maker in a firm}

Following Sims (2003), we model attention as an information flow and limited attention as a constraint on information flow. Decision-makers choose information flows, subject to the constraint on information flow.

To take decisions that are close to the profit-maximizing decisions, agents in firms have to be aware of changes in the environment that cause changes in the profit-maximizing decisions. Being aware of changes in the environment requires information flow when these changes are stochastic. A decision-maker in a firm with limited attention faces a trade-off: Tracking closely particular changes in the environment improves decision making but also uses up valuable information flow. We formalize this trade-off by letting decision-makers in firms choose directly the process for the decision vector, subject to the constraint on information flow. For example, the decision-maker in a firm can decide to respond swiftly and correctly with the price of the good to changes in firmspecific productivity but this requires allocating attention to firm-specific productivity. We assume that decision-makers in firms choose the allocation of attention so as to maximize the expected discounted sum of profits net of the cost of attention. We interpret the cost of attention as an opportunity cost.

\footnotetext{
${ }^{12}$ See Woodford (2003), Chapter 2, Proposition 2.8.
} 
Formally, the attention problem of the decision-maker in firm $i$ reads:

$$
\max _{\kappa, B_{1}(L), B_{2}(L), B_{3}(L), C_{1}(L), C_{2}(L), C_{3}(L), \tilde{\eta}, \chi}\left\{\sum_{t=0}^{\infty} \beta^{t} E_{i,-1}\left[\frac{1}{2}\left(x_{t}-x_{t}^{*}\right)^{\prime} H\left(x_{t}-x_{t}^{*}\right)\right]-\frac{\mu}{1-\beta} \kappa\right\},
$$

where

$$
x_{t}-x_{t}^{*}=\left(\begin{array}{c}
p_{i t} \\
\hat{l}_{i 1 t} \\
\vdots \\
\hat{l}_{i(J-1) t}
\end{array}\right)-\left(\begin{array}{c}
p_{i t}^{*} \\
\hat{l}_{i 1 t}^{*} \\
\vdots \\
\hat{l}_{i(J-1) t}^{*}
\end{array}\right),
$$

subject to the equations characterizing the profit-maximizing decisions

$$
\begin{aligned}
& p_{i t}^{*}=\underbrace{A_{1}(L) \varepsilon_{t}^{A}}_{p_{i t}^{A *}}+\underbrace{A_{2}(L) \varepsilon_{t}^{R}}_{p_{i t}^{R *}}+\underbrace{A_{3}(L) \varepsilon_{i t}^{I}}_{p_{i t}^{I *}} \\
& \hat{l}_{i j t}^{*}=-\eta \hat{w}_{j t},
\end{aligned}
$$

the equations characterizing the actual decisions

$$
\begin{aligned}
& p_{i t}=\underbrace{B_{1}(L) \varepsilon_{t}^{A}+C_{1}(L) \nu_{i t}^{A}}_{p_{i t}^{A}}+\underbrace{B_{2}(L) \varepsilon_{t}^{R}+C_{2}(L) \nu_{i t}^{R}}_{p_{i t}^{R}}+\underbrace{B_{3}(L) \varepsilon_{i t}^{I}+C_{3}(L) \nu_{i t}^{I}}_{p_{i t}^{I}} \\
& \hat{l}_{i j t}=-\tilde{\eta}\left(\hat{w}_{j t}+\frac{\operatorname{Var}\left(\hat{w}_{j t}\right)}{\chi} \nu_{i j t}^{L}\right),
\end{aligned}
$$

and the constraint on information flow

$$
\mathcal{I}\left(\left\{p_{i t}^{A *}, p_{i t}^{R *}, p_{i t}^{I *}, \hat{l}_{i 1 t}^{*}, \ldots, \hat{l}_{i(J-1) t}^{*}\right\} ;\left\{p_{i t}^{A}, p_{i t}^{R}, p_{i t}^{I}, \hat{l}_{i 1 t}, \ldots, \hat{l}_{i(J-1) t}\right\}\right) \leq \kappa
$$

Here $A_{1}(L)$ to $A_{3}(L), B_{1}(L)$ to $B_{3}(L)$, and $C_{1}(L)$ to $C_{3}(L)$ are infinite-order lag polynomials. The noise terms $\nu_{i t}^{A}, \nu_{i t}^{R}, \nu_{i t}^{I}$, and $\nu_{i j t}^{L}$ in the actual decisions are assumed to follow Gaussian white noise processes with unit variance that are: (i) independent of all other stochastic processes in the economy, (ii) firm-specific, and (iii) independent of each other. The operator $\mathcal{I}$ measures the amount of information that the actual decisions contain about the profit-maximizing decisions. This operator is defined below. Finally, $E_{i,-1}$ in objective (75) denotes the expectation operator conditioned on the information of the decision-maker in firm $i$ in period -1 .

The objective (75) states that decision-makers in firms aim to maximize the expected discounted sum of profits net of the cost of information flow. The first term in curly brackets is the expected 
discounted sum of profit losses in the case of deviations of the actual decisions from the profitmaximizing decisions. This term equals the right-hand side of equation (31) in Proposition $1 .{ }^{13}$ The second term in curly brackets is the cost of information flow. The parameter $\mu \geq 0$ is the per-period marginal cost of information flow. We interpret this cost as an opportunity cost (i.e., devoting more attention to the price setting decision or the labor mix decision requires paying less attention to some other decision of the firm that we do not model). The variable $\kappa \geq 0$ is the total information flow devoted to the price setting decision and the labor mix decision.

Equations (77)-(78) characterize the profit-maximizing decisions. We guess that the profitmaximizing price (33) given in Proposition 1 has the representation (77) after substituting in $\hat{p}_{i t}=p_{i t}-p_{t}$, equations (57) and (62), and the equilibrium law of motion for $p_{t}, c_{t}, \tilde{w}_{t}, a_{t}$, and $a_{i t}$. The guess will be verified. The profit-maximizing labor mix (34) given in Proposition 1 reduces to equation (78) after substituting in $\hat{w}_{j t}=\tilde{w}_{j t}-\tilde{w}_{t}$ and equation (62).

Equations (79)-(80) characterize the actual decisions. Consider first equation (79). By choosing the lag polynomials $B_{1}(L)$ and $C_{1}(L)$ to $B_{3}(L)$ and $C_{3}(L)$, the decision-maker chooses the stochastic process for the price. For example, if the decision-maker chooses $B_{1}(L)=A_{1}(L), C_{1}(L)=0$, $B_{2}(L)=A_{2}(L), C_{2}(L)=0, B_{3}(L)=A_{3}(L)$ and $C_{3}(L)=0$, the decision-maker decides to set the actual price equal to the profit-maximizing price in each period. The basic trade-off is the following. Choosing a process for the actual price that tracks more closely the profit-maximizing price reduces profit losses due to suboptimal price setting decisions but requires more attention. Next, consider equation (80). By choosing the coefficients $\tilde{\eta}$ and $\chi$, the decision-maker chooses the wage elasticity of labor demand and the signal-to-noise ratio in the labor mix decision. The basic trade-off is the following. When the profit-maximizing labor mix is stochastic, choosing a process for the actual labor mix that tracks more closely the profit-maximizing labor mix reduces profit losses due to suboptimal hiring decisions but requires more attention. ${ }^{14}$

Finally, the information flow constraint (81) states that actual decisions containing more information about the optimal decisions under perfect information require a larger information flow.

\footnotetext{
${ }^{13}$ In equation (76), we use the fact that $\hat{p}_{i t}-\hat{p}_{i t}^{*}=p_{i t}-p_{i t}^{*}$.

${ }^{14}$ We put more structure on the labor mix decision than on the price setting decision by expressing the labor mix as a function of relative wages rather than fundamental shocks. We do this because from equation (80) we derive the labor demand function and a labor demand function specifies labor demand on and off the equilibrium path. By expressing the labor mix as a function of relative wages, we specify labor demand on and off the equilibrium path.
} 
We follow Sims (2003) and a large literature in information theory by quantifying information as reduction in uncertainty, where uncertainty is measured by entropy. Entropy is simply a measure of uncertainty. The entropy of a normally distributed random vector $X=\left(X_{1}, \ldots, X_{N}\right)$ equals

$$
H(X)=\frac{1}{2} \log _{2}\left[(2 \pi e)^{N} \operatorname{det} \Omega_{X}\right]
$$

where $\operatorname{det} \Omega_{X}$ is the determinant of the covariance matrix of $X$. Conditional entropy is a measure of conditional uncertainty. If the random vectors $X=\left(X_{1}, \ldots, X_{N}\right)$ and $Y=\left(Y_{1}, \ldots, Y_{N}\right)$ have a multivariate normal distribution, the conditional entropy of $X$ given knowledge of $Y$ equals

$$
H(X \mid Y)=\frac{1}{2} \log _{2}\left[(2 \pi e)^{N} \operatorname{det} \Omega_{X \mid Y}\right],
$$

where $\Omega_{X \mid Y}$ is the conditional covariance matrix of $X$ given $Y$. Equipped with measures of uncertainty and conditional uncertainty, one can quantify the information that the random vector $Y$ contains about the random vector $X$ as reduction in uncertainty, $H(X)-H(X \mid Y)$. The operator $\mathcal{I}$ in the information flow constraint (81) is defined as

$$
\mathcal{I}\left(\left\{X_{t}\right\} ;\left\{Y_{t}\right\}\right)=\lim _{T \rightarrow \infty} \frac{1}{T}\left[H\left(X_{0}, \ldots, X_{T-1}\right)-H\left(X_{0}, \ldots, X_{T-1} \mid Y_{0}, \ldots, Y_{T-1}\right)\right],
$$

where $\left\{X_{t}\right\}_{t=0}^{\infty}$ and $\left\{Y_{t}\right\}_{t=0}^{\infty}$ are stochastic processes. The operator $\mathcal{I}$ quantifies the information that one process contains about another process by measuring the average per-period amount of information that the first $T$ elements of one process contain about the first $T$ elements of the other process and by letting $T$ go to infinity. If $\left\{X_{t}, Y_{t}\right\}_{t=0}^{\infty}$ is a stationary Gaussian process, then

$$
\mathcal{I}\left(\left\{X_{t}\right\} ;\left\{Y_{t}\right\}\right)=\lim _{T \rightarrow \infty} \frac{1}{T}\left[\frac{1}{2} \log _{2}\left(\frac{\operatorname{det} \Omega_{X}}{\operatorname{det} \Omega_{X \mid Y}}\right)\right] .
$$

If $X_{t}$ is a scalar then $\Omega_{X}$ is the covariance matrix of the vector $\left(X_{0}, \ldots, X_{T-1}\right)$. If $X_{t}$ is itself a vector then $\Omega_{X}$ is the covariance matrix of the vector obtained by stacking the vectors $X_{0}, \ldots, X_{T-1}{ }^{15}$

To complete the description of the decision problem (75)-(81), we have to specify the expectation operator $E_{i,-1}$ in objective (75). We assume that $E_{i,-1}$ is the unconditional expectation operator.

Note that we have assumed that the actual decisions follow a Gaussian process. One can show that a Gaussian process for the actual decisions is optimal because objective (75) is quadratic

\footnotetext{
${ }^{15}$ If a variable appearing in the information flow constraint (81) is non-stationary, we replace the original variable by its first difference on the left-hand side of (81) to ensure that entropy is always finite. Replacing a stationary variable by its first difference on the left-hand side of (81) has no effect on information flow.
} 
and the profit-maximizing decisions (77)-(78) follow a Gaussian process. ${ }^{16}$ Furthermore, we have assumed that the noise in the actual decisions is firm-specific. This assumption accords well with the idea that the friction is the limited attention of an individual decision-maker rather than the public availability of information. Finally, we have assumed that the noise terms $\nu_{i t}^{A}, \nu_{i t}^{R}, \nu_{i t}^{I}$, and $\nu_{i j t}^{L}$ are independent of each other. This assumption captures the idea that attending to aggregate technology, attending to monetary policy, attending to firm-specific productivity, and attending to relative wage rates are independent activities. We relax this assumption in Section 7.5.

Two remarks are in place before we present solutions of the decision problem (75)-(81). When we solve the decision problem (75)-(81) numerically, we turn this infinite-dimensional problem into a finite-dimensional problem by parameterizing each infinite-order lag polynomial $B_{1}(L)$ to $B_{3}(L)$ and $C_{1}(L)$ to $C_{3}(L)$ as a lag-polynomial of an $\operatorname{ARMA}(\mathrm{p}, \mathrm{q})$ process where $p$ and $q$ are finite. ${ }^{17}$ Furthermore, we evaluate the right-hand side of equation (83) for a very large but finite $T$.

\subsection{Computing the equilibrium of the model}

We use an iterative procedure to solve for the rational expectations equilibrium of the model with rational inattention by decision-makers in firms and perfect information by households. First, we make a guess concerning the stochastic process for the profit-maximizing price (77) and a guess concerning the stochastic process for the relative wage rate in equation (78). Second, we solve the firms' attention problem (75)-(81). Third, we aggregate the individual prices to obtain the aggregate price level

$$
p_{t}=\frac{1}{I} \sum_{i=1}^{I} p_{i t} .
$$

Fourth, we compute the aggregate dynamics implied by those price level dynamics. The households' optimality conditions (52)-(54) given in Proposition 2, equations (56)-(66), $y_{i t}=c_{i t}$, and the assumption that aggregate technology follows a first-order autoregressive process imply that the following equations have to be satisfied in equilibrium:

$$
c_{t}=E_{t}\left[-\frac{1}{\gamma}\left(r_{t}-p_{t+1}+p_{t}\right)+c_{t+1}\right]
$$

\footnotetext{
${ }^{16}$ See Sims (2006) or Section VIIA in Maćkowiak and Wiederholt (2009).

${ }^{17}$ We set $p=2$ and $q=2$, because we found that increasing $p$ or $q$ further failed to change noticeably the solution.
} We allow the $\operatorname{ARMA}(\mathrm{p}, \mathrm{q})$ process to have a unit root. 


$$
\begin{gathered}
\tilde{w}_{t}=\gamma c_{t}+\psi l_{t}, \\
y_{t}=c_{t}, \\
y_{t}=a_{t}+\alpha l_{t}, \\
a_{t}=\rho_{A} a_{t-1}+\varepsilon_{t}^{A}, \\
r_{t}=\rho_{R} r_{t-1}+\left(1-\rho_{R}\right)\left[\phi_{\pi}\left(p_{t}-p_{t-1}\right)+\phi_{y} y_{t}\right]+\varepsilon_{t}^{R},
\end{gathered}
$$

where $E_{t}$ denotes the expectation operator conditioned on the entire history of the economy up to and including period $t$. We employ a standard solution method for linear rational expectations models to solve the system of equations containing the price level dynamics and those six equations. We obtain the law of motion for $\left(c_{t}, \tilde{w}_{t}, y_{t}, l_{t}, a_{t}, r_{t}\right)$ implied by the price level dynamics. Fifth, we compute the law of motion for the profit-maximizing price. The equation for the profit-maximizing price (33), $\hat{p}_{i t}=p_{i t}-p_{t}$ and equations (57) and (62) imply that the profit-maximizing price equals

$$
p_{i t}^{*}=p_{t}+\frac{\frac{1-\alpha}{\alpha}}{1+\frac{1-\alpha}{\alpha} \tilde{\theta}} c_{t}+\frac{1}{1+\frac{1-\alpha}{\alpha} \tilde{\theta}} \tilde{w}_{t}-\frac{\frac{1}{\alpha}}{1+\frac{1-\alpha}{\alpha} \tilde{\theta}}\left(a_{t}+a_{i t}\right) .
$$

Substituting the law of motion for $p_{t}, c_{t}, \tilde{w}_{t}, a_{t}$ and $a_{i t}$ into the last equation yields the law of motion for the profit-maximizing price. We set $\tilde{\theta}=\theta$ in the last equation because the households' optimality condition (54) given in Proposition 2 and equations (57), (59) and (63) imply that the demand function for good $i$ has the form (18)-(20) with a price elasticity of demand equal to $\theta$. Sixth, if the law of motion for the profit-maximizing price differs from our guess, we update the guess until a fixed point is reached. ${ }^{18}$

Finally, we derive equilibrium relative wage rates. When households have perfect information, equilibrium relative wage rates can be derived analytically. In particular, it is an equilibrium that relative wage rates are constant. The argument is as follows. Suppose that all firms choose the same values for $\tilde{\eta}$ and $\chi$ satisfying $\tilde{\eta}>1$ and $\chi>0$. Then, equations (80), (58) and (64) imply that the labor demand function for type $j$ labor has the form (35)-(37) with a wage elasticity of

\footnotetext{
${ }^{18}$ We use Matlab and a standard nonlinear optimization program to solve the firms' attention problem. The solution of the firms' attention problem takes about 20 seconds on a machine on which the LU decomposition of a full matrix requires about 0.1 of one second (as reported by the Matlab function bench.m). On the way to a fixed point, we make the guess in iteration $n$ a weighted average of the solution in iteration $n-1$ and the guess in iteration $n-1$. The number of iterations needed to reach a fixed point depends significantly on parameter values, on the initial guess, on the weight of the guess in iteration $n-1$ in the guess in iteration $n$, and on the terminal condition.
} 
labor demand that is the same for all types of labor. Since all households face the same decision problem and have the same information, all households set the same wage rate. Equation (62) then implies that relative wage rates are constant $\left(\hat{w}_{j t}=w_{j t}-w_{t}=0\right)$. When relative wage rates are constant, the profit-maximizing labor mix is constant, implying that each firm can attain the profit-maximizing labor mix without any information flow. Since each firm can attain the profitmaximizing labor mix without any information flow, no firm has an incentive to deviate from the chosen values for $\tilde{\eta}$ and $\chi$.

\subsection{Benchmark parameter values and solution}

Next we report the numerical solution of the model for the following parameter values. One period in the model is one quarter. We set $\beta=0.99, \gamma=1, \psi=0, \theta=4, \alpha=2 / 3$, and $\eta=4$.

To set the parameters of the first-order autoregressive process for aggregate technology, we consider quarterly U.S. data from 1960 Q1 to 2006 Q4 and we use equations (88)-(89). We first compute a time series for aggregate technology, $a_{t}$, using equation (88) and measures of $y_{t}$ and $l_{t}$. We use the log of real output per person, detrended with a linear trend, as a measure of $y_{t}$. We use the log of hours worked per person, demeaned, as a measure of $l_{t} \cdot{ }^{19}$ We then fit equation (89) to the time series for $a_{t}$ obtaining $\rho_{A}=0.96$ and a standard deviation of the innovation equal to 0.0085. In the benchmark economy, we set $\rho_{A}=0.95$ and the standard deviation of $\varepsilon_{t}^{A}$ equal to 0.0085 .

To set the parameters of the monetary policy rule, we estimate the Taylor rule (90) with the quarterly U.S. data on the Federal Funds rate, inflation, and real GDP from 1960 Q1 to 2006 Q4. We obtain $\rho_{R}=0.89, \phi_{\pi}=1.53, \phi_{y}=0.33$, and a standard deviation of the innovation equal to $0.0021 .{ }^{20}$ In the benchmark economy, we set $\rho_{R}=0.9, \phi_{\pi}=1.5, \phi_{y}=0.33$, and the standard

\footnotetext{
${ }^{19}$ We use data for the non-farm business sector. The data source is the website of the Federal Reserve Bank of St. Louis.

${ }^{20}$ The specification of the monetary policy rule that we estimate is standard in the empirical literature on the Taylor rule with partial adjustment. See, for example, Section 2 in Rudebusch (2002) for a review of this literature. We regress a measure of the nominal interest rate on its own lag, a measure of the inflation rate, and a measure of the output gap. The nominal interest rate is measured as the quarterly average Federal Funds rate. The inflation rate is measured as $\frac{1}{4} \sum_{l=0}^{3} \pi_{t-l}$, where $\pi_{t}=\ln P_{t}-\ln P_{t-1}$ and $P_{t}$ is the price index for personal consumption expenditures excluding food and energy. The output gap is measured as $\left(Y_{t}-Y_{t}^{p}\right) / Y_{t}^{p}$, where $Y_{t}$ is real GDP and $Y_{t}^{p}$ is potential real GDP estimated by the Congressional Budget Office. The data sources are the website of the Federal Reserve
} 
deviation of $\varepsilon_{t}^{R}$ equal to $0.0021 .^{21}$

To set the parameters of the first-order autoregressive process for firm-specific productivity, we follow the recent literature calibrating menu cost models with firm-specific productivity shocks to U.S. micro price data. Nakamura and Steinsson (2008) and Bils, Klenow and Malin (2009) set the autocorrelation of firm-specific productivity in their monthly models equal to 0.66 and 0.7 , respectively. We set the autocorrelation of firm-specific productivity equal to 0.3 because our model is quarterly not monthly and $(0.3)^{1 / 3}$ equals a number between 0.66 and 0.7 . Furthermore, Klenow and Kryvtsov (2008) report that the median absolute size of price changes (excluding sale-related price changes) equals 9.7 percent in the U.S. We set the standard deviation of the innovation to firm-specific productivity such that the median absolute size of price changes equals 9.7 percent in our model. This choice yields a standard deviation of the innovation to firm-specific productivity equal to $0.18 .^{22}$

We compute the solution of the model by fixing the marginal cost of information flow, $\mu \geq 0$. The total information flow devoted to the price setting decision and the labor mix decision (i.e., $\kappa)$ is endogenous. We interpret the marginal cost of information flow as an opportunity cost (i.e., the extra attention devoted to the price setting decision or the labor mix decision could have been devoted to some other decision of the firm that we do not model). We set the marginal cost of information flow equal to 0.1 percent of the firm's steady state revenue. In objective (75) we value this cost using the value of the stochastic discount factor at the non-stochastic steady state. This yields $\mu=(0.001)\left(1+\tau_{p}\right) \hat{P}_{i} Y_{i} C_{j}^{-\gamma}$. This value for the marginal cost of attention implies that in equilibrium the expected per-period loss in profit due to deviations of the actual price from the Bank of St. Louis and the website of the Congressional Budget Office. Note that in the empirical monetary policy rule we measure the inflation rate as the four-quarter moving average of inflation rates. We do so following Section 2 in Rudebusch (2002). Using only the current inflation rate in the empirical monetary policy rule yields essentially identical estimates.

${ }^{21}$ We investigated the role of all parameters in the model. We report the effects of changes in parameter values in Section 7.4. Note that restricting the sample to the Great Moderation would have yielded a smaller standard deviation of the innovation in the Taylor rule. In the model this would imply less attention to monetary policy compared with the benchmark economy.

${ }^{22}$ Note that we match the average size of price changes excluding sale-related price changes. If we were to match the average size of all price changes, the standard deviation of the innovation to firm-specific productivity would be even larger. 
profit-maximizing price equals 0.15 percent of the firm's steady state revenue: $(0.0015)\left(1+\tau_{p}\right) \hat{P}_{i} Y_{i}$. We find this number reasonable. ${ }^{23}$

We first report the optimal allocation of attention at the equilibrium with rational inattention by decision-makers in firms. Decision-makers in firms who have to set prices decide to pay most attention to firm-specific productivity, quite a bit of attention to aggregate technology, and little attention to monetary policy. More precisely, of the total attention devoted to the price setting decision, 65 percent is allocated to firm-specific productivity, 26 percent is allocated to aggregate technology, and 9 percent is allocated to monetary policy. Therefore, prices respond very quickly to market-specific shocks, fairly quickly to aggregate technology shocks, and slowly to monetary policy shocks. The empirical literature finds in the data the same mix of quick and slow responses of prices to shocks. Furthermore, for our value of the marginal cost of information flow, the total attention devoted to the price setting decision is sufficiently high so that the actual price set by a firm tracks the profit-maximizing price very well. The expected per-period loss in profit due to deviations of the actual price from the profit-maximizing price equals 0.15 percent of the firm's steady state revenue. ${ }^{24}$ As we will point out below, this number for the expected loss in profit due to deviations of the actual price from the profit-maximizing price is 30 times smaller than in the Calvo model that yields the same responses of the price level and output to monetary policy shocks.

Figures 1 and 2 show impulse responses of the price level, inflation, output, and the nominal interest rate at the equilibrium with rational inattention by decision-makers in firms and perfect information by households (green lines with circles). For comparison, the figures also include impulse responses of the same variables at the equilibrium under perfect information derived in Section 6 (blue lines with points). All impulse responses are to shocks of one standard deviation. A response equal to one means a one percent deviation from the non-stochastic steady state. Time

\footnotetext{
${ }^{23}$ To illustrate this number, consider the following example. Suppose that the firm with a rationally inattentive decision-maker has a profit margin of 15 percent. If the decision-maker of the firm set the profit-maximizing price in each period, the profit margin would increase to 15.15 percent. Hence, if one part of the decision-maker's compensation is proportional to the profit margin, this part of the decision-maker's compensation would increase by $(1 / 100)$.

${ }^{24}$ The expected per-period profit loss due to imperfect tracking of firm-specific productivity equals 0.07 percent of the firm's steady state revenue. The expected per-period profit loss due to imperfect tracking of aggregate technology equals 0.05 percent of the firm's steady state revenue. The expected per-period profit loss due to imperfect tracking of monetary policy equals 0.03 percent of the firm's steady state revenue.
} 
is measured in quarters along horizontal axes.

Consider Figure 1. Under rational inattention by decision-makers in firms, the price level shows a dampened and delayed response to a monetary policy shock (compared with the case of perfect information). The response of inflation to a monetary policy shock is persistent. Since the price level responds slowly to a monetary policy shock, the real interest rate increases after a positive innovation in the Taylor rule, implying that consumption and output fall. The fall in output is persistent. The nominal interest rate increases on impact of a monetary policy shock and then converges slowly to zero. By contrast, under perfect information by firms and households, the price level adjusts fully on impact of a monetary policy shock, there are no real effects, and the nominal interest rate fails to change.

Consider Figure 2. The response of the price level to aggregate technology shocks is to some extent dampened and delayed (compared with the case of perfect information). Therefore, output is below perfect-information output for a few quarters after a positive aggregate technology shock, implying that output shows a hump-shaped impulse response to an aggregate technology shock. However, the response of the price level to aggregate technology shocks is stronger and faster than the response of the price level to monetary policy shocks. The reason is that decision-makers in firms decide to pay about three times as much attention to aggregate technology than to monetary policy. ${ }^{25}$

Figure 3 shows the impulse response of an individual price to a firm-specific productivity shock. Prices respond very quickly to firm-specific productivity shocks. The reason is that decision-makers in firms decide to pay close attention to firm-specific productivity.

Figures 1-3 show that the model matches the following three empirical findings: (i) the model matches the empirical finding by Boivin, Giannoni and Mihov (2009) and Maćkowiak, Moench and Wiederholt (2009) that prices respond very quickly to disaggregate shocks, (ii) the model matches the empirical finding by Altig, Christiano, Eichenbaum and Linde (2005) that the price level responds faster to aggregate technology shocks than to monetary policy shocks, and (iii) the model matches the empirical finding that the price level responds slowly to monetary policy shocks. ${ }^{26}$ The model matches this mix of very quick, fairly quick and slow responses of prices to

\footnotetext{
${ }^{25}$ The difference between the response of the price level to monetary policy shocks and the response of the price level to aggregate technology shocks becomes even more pronounced once we introduce rational inattention by households.

${ }^{26} \mathrm{~A}$ number of different identification assumptions lead to the finding that the price level responds slowly to
} 
shocks with an endogenous allocation of attention. The reason is the following. When we calibrate the model so as to match key features of the U.S. data like the large average absolute size of price changes in micro data and the small standard deviation of the innovation in the Taylor rule, most of the variation in the profit-maximizing price is due to market-specific shocks, considerable variation in the profit-maximizing price is due to aggregate technology shocks, and little variation in the profit-maximizing price is due to monetary policy shocks. Decision-makers in firms who are responsible for setting prices therefore pay close attention to market-specific conditions, quite a bit of attention to aggregate technology, and little attention to monetary policy. ${ }^{27}$

For comparison, we solved the Calvo model with the same preference, technology, and monetary policy parameters. The motivation for this comparison is that the Calvo model is the most commonly used model for monetary policy analysis. We set the Calvo parameter so that prices in the Calvo model change every 2.5 quarters on average because then the impulse responses to a monetary policy shock are essentially identical in the Calvo model with perfect information and in our benchmark economy with rational inattention by decision-makers in firms. See Figure 4 . While the impulse responses to a monetary policy shock are essentially identical in the two models, the impulse responses to an aggregate technology shock are very different in the two models. See Figure 5. The response of the price level to an aggregate technology shock is stronger and faster in the benchmark economy than in the Calvo model, implying that output deviates from the efficient level of output for only 5 quarters in our benchmark economy while output deviates from the efficient level of output for more than 20 quarters in the Calvo model. Hence, after an aggregate technology shock, the rational inattention model is much closer to a frictionless economy than the Calvo model. Furthermore, after a firm-specific productivity shock, the rational inattention model behaves essentially like a frictionless economy while there are large distortions in the Calvo model.

In the benchmark economy and in the Calvo model, firms experience profit losses due to deviations of the actual price from the profit-maximizing price. In the benchmark economy, the expected loss in profit due to deviations of the actual price from the profit-maximizing price is 30 monetary policy shocks. See, for example, Christiano, Eichenbaum and Evans (1999), Leeper, Sims and Zha (1996), and Uhlig (2005).

${ }^{27}$ There is also the amplification effect highlighted in Maćkowiak and Wiederholt (2009) and Hellwig and Veldkamp (2009). If other firms pay little attention to say monetary policy, the profit-maximizing price moves less in response to a monetary policy shock, which reduces the incentive for an individual firm to pay attention to monetary policy. 
times smaller than in the Calvo model that yields the same impulse responses of the price level and output to a monetary policy shock. ${ }^{28}$ The main reason is that in the benchmark economy prices respond slowly to monetary policy shocks, but fairly quickly to aggregate technology shocks and very quickly to market-specific shocks. The other reason is that in the rational inattention model deviations of the actual price from the profit-maximizing price are less likely to be extreme than in the Calvo model.

\subsection{The effects of changes in parameter values}

We now study whether the model yields different counterfactuals than other DSGE models (e.g., the Calvo model, a model with exogenous dispersed information, or the sticky information model). Does it matter whether one uses this model or another DSGE model for policy analysis? We conduct standard experiments like increasing the coefficient on inflation in the Taylor rule and raising strategic complementarity in price setting. We find that the outcomes of experiments conducted with this model are very different from the outcomes of the same experiments conducted with other DSGE models. The reason is that the allocation of attention is endogenous.

For example, let us vary the coefficient on inflation in the Taylor rule. Figure 6 shows the effect of increasing $\phi_{\pi}$ from 1.05 to 1.5 (our benchmark value) and then to 10 on the volatility of the output gap. ${ }^{29}$ We report the standard deviation of the output gap due to aggregate technology shocks and the standard deviation of the output gap due to monetary policy shocks. As $\phi_{\pi}$ increases in the rational inattention model, the standard deviation of the output gap due to aggregate technology shocks first rises, peaking at 1.75, and then falls. The standard deviation of the output gap due to monetary policy shocks is essentially constant until 1.75 and then rises. For comparison, as $\phi_{\pi}$ increases in the Calvo model, the standard deviation of the output gap due to aggregate technology shocks declines monotonically and the standard deviation of the output gap due to monetary policy shocks declines monotonically. Hence, the rational inattention model yields a very different

\footnotetext{
${ }^{28}$ The expected loss in profit due to suboptimal price responses to aggregate conditions is about 20 times smaller than in the Calvo model. The expected loss in profit due to suboptimal price responses to idiosyncratic conditions is about 40 times smaller than in the Calvo model.

${ }^{29}$ We define the output gap as the deviation of aggregate output from equilibrium aggregate output under perfect information given in Proposition 3. Due to the subsidies (10)-(11), equilibrium aggregate output under perfect information also equals efficient aggregate output.
} 
answer to the basic policy question of what happens when the central bank fights inflation more aggressively.

To understand how the value of $\phi_{\pi}$ affects the economy in the two models, note the following. As $\phi_{\pi}$ increases in the Calvo model, the nominal interest rate mimics more closely the real interest rate at the efficient solution. This effect reduces deviations of output from the efficient solution. In the rational inattention model, there is an additional effect. When the central bank responds more aggressively with the nominal interest rate to inflation, the price level becomes more stable, implying that decision-makers in firms decide to pay less attention to aggregate conditions. This effect increases deviations of output from the efficient solution. When the second effect dominates the first effect, the volatility of the output gap increases. For aggregate technology shocks the second effect dominates for values of $\phi_{\pi}$ below 1.75, while for monetary policy shocks the second effect dominates for values of $\phi_{\pi}$ above 1.75 .

Second, consider raising strategic complementarity in price setting. There is a large literature arguing that raising strategic complementarity in price setting increases real effects of monetary policy shocks. For example, Woodford (2003, Chapter 3) makes this point for the Calvo model and Woodford (2002) makes this point for a model with exogenous dispersed information. A common way to raise strategic complementarity in price setting is to make a firm's marginal cost curve more upward sloping in own output. See, for example, Altig, Christiano, Eichenbaum and Linde (2005). We therefore consider the experiment of making a firm's marginal cost curve more upward sloping in own output. In particular, we raise the degree of decreasing returns-to-scale, $(1 / \alpha)$. When we decrease $\alpha$ from 1 to $2 / 3$ (our benchmark value) and then to $1 / 2$, real effects of monetary policy shocks first increase and then decrease. The reason is that there are two effects. The first effect is the effect emphasized in the literature cited above. In the benchmark economy, a decrease in $\alpha$ lowers the coefficient on consumption in the equation for the profit-maximizing price. Formally, substituting equations (86)-(88) and $\tilde{\theta}=\theta$ into equation (91) yields the following equation for the profit-maximizing price

$$
p_{i t}^{*}=p_{t}+\frac{\frac{1-\alpha}{\alpha}+\gamma+\frac{\psi}{\alpha}}{1+\frac{1-\alpha}{\alpha} \theta} c_{t}-\frac{\frac{\psi}{\alpha}+\frac{1}{\alpha}}{1+\frac{1-\alpha}{\alpha} \theta} a_{t}-\frac{\frac{1}{\alpha}}{1+\frac{1-\alpha}{\alpha} \theta} a_{i t} .
$$

A decrease in $\alpha$ lowers the coefficient on consumption in equation (92) so long as $\theta(\gamma+\psi)>(1+\psi)$ which is a parameter restriction that is satisfied in the benchmark economy. In the language of Woodford (2003), a decrease in $\alpha$ raises the degree of strategic complementarity in price setting. 
In the language of Ball and Romer (1990), a decrease in $\alpha$ raises the degree of real rigidity. This effect increases real effects of monetary policy shocks. However, in the rational inattention model, there is an additional effect. As $\alpha$ decreases, the cost of a price setting mistake of a given size increases. Formally, the upper-left element of the matrix $H$ in Proposition 1 increases in absolute value. Decision-makers in firms therefore decide to pay more attention to the price setting decision, implying that prices respond faster to shocks. This effect reduces real effects of monetary policy shocks. We find that the second effect (more attention) dominates the first effect (lower coefficient on consumption in the equation for the profit-maximizing price) for values of $\alpha$ below $2 / 3$. Hence, for reasonable parameter values, raising strategic complementarity reduces real effects.

Third, consider increasing the variance of monetary policy shocks. In the rational inattention model, decision-makers in firms decide to pay more attention to monetary policy, implying that prices respond faster to monetary policy shocks and real effects of a monetary policy shock of a given size decrease. In the Calvo model, increasing the variance of monetary policy shocks has no effect on the responses of prices and output to a monetary policy shock of a given size. The reallocation of attention in the rational inattention model is important quantitatively. For example, in the benchmark economy, doubling the standard deviation of monetary policy shocks implies that real effects of monetary policy shocks last only 4 quarters instead of 10 quarters.

We could present the outcomes of many more experiments. The point is: the outcomes of experiments are very different than in DSGE models currently used at central banks. Moreover, there is a clear intuition for why the outcomes are so different: the allocation of attention varies with the economic environment.

\subsection{Extension: Signals}

In this subsection we state the attention problem of the decision-maker in a firm using signals. We also relax the assumption that attending to aggregate technology, attending to monetary policy, and attending to firm-specific productivity are independent activities.

We now assume that, in period -1 , the decision-maker in a firm chooses the precision of the signals that he or she will receive in the following periods. In each period $t \geq 0$, the decision-maker receives the signals and takes the optimal price setting and labor mix decision given the signals. The decision-maker chooses the precision of the signals in period -1 so as to maximize the expected 
discounted sum of profits net of the cost of information flow. The decision-maker understands that a more precise signal will lead to better decision making but will also require more attention. Formally, the attention problem of the decision-maker in firm $i$ reads:

$$
\max _{\left(\kappa, \sigma_{1}, \sigma_{2}, \sigma_{3}, \sigma_{4}\right) \in \mathbf{R}_{+}^{5}}\left\{\sum_{t=0}^{\infty} \beta^{t} E_{i,-1}\left[\frac{1}{2}\left(x_{t}-x_{t}^{*}\right)^{\prime} H\left(x_{t}-x_{t}^{*}\right)\right]-\frac{\mu}{1-\beta} \kappa\right\},
$$

where

$$
x_{t}-x_{t}^{*}=\left(\begin{array}{c}
p_{i t} \\
\hat{l}_{i 1 t} \\
\vdots \\
\hat{l}_{i(J-1) t}
\end{array}\right)-\left(\begin{array}{c}
p_{i t}^{*} \\
\hat{l}_{i 1 t}^{*} \\
\vdots \\
\hat{l}_{i(J-1) t}^{*}
\end{array}\right),
$$

subject to equations (77)-(78) characterizing the profit-maximizing decisions, the following equation characterizing the optimal decisions in period $t$ given information in period $t$

$$
x_{t}=E\left[x_{t}^{*} \mid \mathcal{F}_{i 0}, s_{i 1}, s_{i 2}, \ldots, s_{i t}\right],
$$

the following equation characterizing the signal vector in period $t$

$$
s_{i t}=\left(\begin{array}{c}
p_{i t}^{A *} \\
p_{i t}^{R *} \\
p_{i t}^{I *} \\
\hat{w}_{1 t} \\
\vdots \\
\hat{w}_{(J-1) t}
\end{array}\right)+\left(\begin{array}{c}
\sigma_{1} \nu_{i t}^{A} \\
\sigma_{2} \nu_{i t}^{R} \\
\sigma_{3} \nu_{i t}^{I} \\
\sigma_{4} \nu_{i 1 t}^{L} \\
\vdots \\
\sigma_{4} \nu_{i(J-1) t}^{L}
\end{array}\right),
$$

and the constraint on information flow

$$
\mathcal{I}\left(\left\{p_{i t}^{A *}, p_{i t}^{R *}, p_{i t}^{I *}, \hat{l}_{i 1 t}^{*}, \ldots, \hat{l}_{i(J-1) t}^{*}\right\} ;\left\{s_{i t}\right\}\right) \leq \kappa .
$$

The noise terms $\nu_{i t}^{A}, \nu_{i t}^{R}, \nu_{i t}^{I}$, and $\nu_{i 1 t}^{L}$ to $\nu_{i(J-1) t}^{L}$ in the signal are assumed to follow Gaussian white noise processes with unit variance that are: (i) independent of all other stochastic processes in the economy, (ii) firm-specific, and (iii) independent of each other. As in the decision problem (75)(81), $E_{i,-1}$ in objective (93) denotes the expectation operator conditioned on the information of the decision-maker in firm $i$ in period -1 , the parameter $\mu \geq 0$ in objective (93) is the marginal cost of information flow, and the operator $\mathcal{I}$ in the information flow constraint (97) is defined by equation 
(82). We assume that $E_{i,-1}$ is the unconditional expectation operator. Finally, $\mathcal{F}_{i 0}$ in equation (95) denotes the information set of the decision-maker in firm $i$ in period zero. To abstract from transitional dynamics in conditional second moments, we assume that in period zero (i.e., after the decision-maker has chosen the precision of the signals in period -1), the decision-maker receives information such that the conditional covariance matrix of $x_{t}^{*}$ given information in period $t$ is constant for all $t \geq 0$.

We solve the problem (93)-(97) for an individual firm assuming that aggregate variables and relative wage rates are given by the equilibrium of the benchmark economy presented in Section 7.3. In other words, we assume that the behavior of all other firms and all households is given by the benchmark economy presented in Section 7.3. We then compare the solution of problem (93)-(97) to the solution of problem (75)-(81). Consider the left column of Figure 7. The blue lines with points show the impulse responses of the profit-maximizing price to the three fundamental shocks at the equilibrium presented in Section 7.3. The green lines with circles show the impulse responses of the price set by the firm to the three fundamental shocks when the firm solves problem (75)-(81). The red lines with crosses show the impulse responses of the price set by the firm to the three fundamental shocks when the firm solves problem (93)-(97). The decision problems (75)-(81) and (93)-(97) yield the same price setting behavior: the green lines with circles and the red lines with crosses in Figure 7 are identical, and the impulse responses of the price set by the firm to the noise terms in equation (79) and to the noise terms in equation (96) also turn out to be identical. ${ }^{30,31}$

\footnotetext{
${ }^{30}$ We solve problem (93)-(97) numerically using Matlab and a standard nonlinear optimization program. We first approximate each of the following four objects by an ARMA(p,q) process where $p$ and $q$ are finite: the component of $p_{t}$ driven by aggregate technology shocks, the component of $p_{t}$ driven by monetary policy shocks, the component of $c_{t}$ driven by aggregate technology shocks, and the component of $c_{t}$ driven by monetary policy shocks. Then, there exists a state-space representation of the dynamics of the signal (96) with a finite-dimensional state vector. We use the Kalman filter to evaluate objective (93) and constraint (97) for any given choice of the precision of the signals. We employ the program kfilter.m, written by Lars Ljungqvist and Thomas J. Sargent, to solve for the conditional covariance matrix of the state vector. Solving the problem (93)-(97) takes about as much time as solving the problem (75)-(81). See Footnote 18. Below we also present solutions of problem (93)-(97) with the signal vector (98) instead of the signal vector (96). Solving that problem turned out to be much more time-consuming. Here we had to evaluate objective (93) and constraint (97) on a grid. Standard nonlinear optimization programs proved unhelpful because numerical inaccuracy in the solution for the conditional covariance matrix of the state vector led to spurious variation in the values of the objective and the constraint.

${ }^{31}$ This is a numerical result. We were surprised that signals with noise that is i.i.d. across time yield the same
} 
We now relax the assumption that paying attention to aggregate technology, paying attention to monetary policy, and paying attention to firm-specific productivity are independent activities. We replace the signal vector (96) by the following signal vector

$$
s_{i t}=\left(\begin{array}{c}
p_{t} \\
a_{t}+a_{i t} \\
c_{i, t-1} \\
w_{t-1}+l_{i, t-1} \\
\hat{w}_{1 t} \\
\vdots \\
\hat{w}_{(J-1) t}
\end{array}\right)+\left(\begin{array}{c}
\sigma_{1} \nu_{i 1 t} \\
\sigma_{2} \nu_{i 2 t} \\
\sigma_{3} \nu_{i 3 t} \\
\sigma_{4} \nu_{i 4 t} \\
\sigma_{5} \nu_{i 1 t}^{L} \\
\vdots \\
\sigma_{5} \nu_{i(J-1) t}^{L}
\end{array}\right) .
$$

By choosing $\sigma_{1}$ to $\sigma_{5}$ the decision-maker decides how much attention to devote to the price level, total factor productivity, last period sales, the last period wage bill, and the relative wage rates. ${ }^{32,33}$ The variables in the signal vector (98) are driven by multiple shocks and it is therefore no longer the case that attending to aggregate technology, attending to monetary policy, and attending to firm-specific productivity are independent activities. We find that solving the problem (93)-(97) with the signal vector (98) instead of the signal vector (96) changes the firm's price setting behavior hardly at all. See the right column of Figure 7. The price set by the firm responds somewhat faster to aggregate technology shocks and somewhat slower to monetary policy shocks. Overall the red lines with crosses in the right column of Figure 7 are very similar to the red lines with crosses in the left column of Figure 7. The reason is that the decision-maker in the firm decides to pay close attention to those variables that are mainly driven by firm-specific productivity shocks and aggregate technology shocks.

We studied a large number of variations of the signal vector (98) and obtained similar results. First, we added other aggregate variables one by one to the signal vector. We found little or price setting behavior as the more flexible decision problem (75)-(81).

${ }^{32}$ We maintain the assumption that the noise terms follow unit variance Gaussian white noise processes that are: (i) independent of all other stochastic processes in the economy, (ii) firm-specific, and (iii) independent of each other.

${ }^{33} \mathrm{We}$ include last period sales and last period wage bill in the signal vector because we do not know how the firm can attend to current period sales and current period wage bill before setting the price. Below, when we do assume that the firm can attend to current period sales and current period wage bill, we mean that the firm can attend to the components of current period sales and current period wage bill that are independent of the own price, that is, $\theta p_{t}+c_{t}$ and $w_{t}+(1 / \alpha)\left(\theta p_{t}+c_{t}-a_{t}-a_{i t}\right)$, respectively. 
no effect on the price setting behavior because the decision-maker of the firm decided to set the precision of the additional signal to a small number or zero. Second, we replaced last period sales and last period wage bill by current period sales and current period wage bill in the signal vector. The price set by the firm then responds somewhat faster to aggregate technology shocks and to monetary policy shocks, but the price still responds faster to aggregate technology shocks than to monetary policy shocks. Third, we added firm-specific demand shocks to the model by modifying the consumption aggregator (2). We kept constant the variance of the firm-specific component of the profit-maximizing price. We split this variance equally between firm-specific productivity shocks and firm-specific demand shocks. We assumed the same persistence in firm-specific productivity and firm-specific demand. We then solved again the decision problem (93)-(97) with the signal vector (98). We found that adding firm-specific demand shocks had almost no effect on the impulse responses of the price set by the firm to the other shocks. We obtained impulse responses that were almost identical to the red lines with crosses in the right column of Figure $7{ }^{34}$

\section{Rational inattention by households and firms}

In this section we solve the model with rational inattention by households and firms.

To exhibit in the most transparent way the implications of rational inattention by households for the intertemporal consumption decision, we make two assumptions in Sections 8.1-8.4. First, we continue to assume that households have linear disutility of labor. Then the equation for the optimal real wage rate, stating that the real wage rate should equal the marginal rate of substitution between consumption and leisure, reduces to

$$
\tilde{w}_{j t}=\gamma c_{j t}
$$

where $\tilde{w}_{j t}$ is the real wage rate for type $j$ labor and $c_{j t}$ is composite consumption by household $j$. Second, we assume that households set real wage rates. Then households choose all variables in

\footnotetext{
${ }^{34}$ Hellwig and Venkateswaran (2009) also study a model in which firms set prices in period $t$ based on signals concerning sales and wage bills up to and including period $t-1$. There are several differences. First, in their benchmark model the price level and total factor productivity are not included in the signal vector. More importantly, in their model the noise in the signal is exogenous, whereas in our model the noise in the signal (98) is chosen optimally subject to the constraint on information flow (97). In other words, they report impulse responses for some exogenously given precision of the signals, whereas we report impulse responses for the optimal precision of the signals.
} 
the intratemporal optimality condition (99). Therefore, households will satisfy this intratemporal optimality condition both under perfect information and under rational inattention. This allows us to exhibit in the most transparent way the implications of rational inattention by households for the intertemporal consumption decision. In Section 8.5, we also present the solution of the model when households set nominal wage rates. ${ }^{35}$

\subsection{The attention problem of a household}

The attention problem of household $j$ in period -1 reads:

$\max _{\kappa, B_{1}(L), B_{2}(L), C_{1}(L), C_{2}(L), \tilde{\theta}, \xi}\left\{\begin{array}{c}\sum_{t=0}^{\infty} \beta^{t} E_{j,-1}\left[\frac{1}{2}\left(x_{t}-x_{t}^{*}\right)^{\prime} H_{0}\left(x_{t}-x_{t}^{*}\right)+\left(x_{t}-x_{t}^{*}\right)^{\prime} H_{1}\left(x_{t+1}-x_{t+1}^{*}\right)\right] \\ -\frac{\lambda}{1-\beta} \kappa\end{array}\right\}$,

where

$$
x_{t}-x_{t}^{*}=\left(\begin{array}{c}
\tilde{b}_{j t} \\
\tilde{w}_{j t} \\
\hat{c}_{1 j t} \\
\vdots \\
\hat{c}_{I-1 j t}
\end{array}\right)-\left(\begin{array}{c}
\tilde{b}_{j t}^{*} \\
\tilde{w}_{j t}^{*} \\
\hat{c}_{1 j t}^{*} \\
\vdots \\
\hat{c}_{I-1 j t}^{*}
\end{array}\right),
$$

subject to the following equation linking an argument of the objective and two decision variables

$$
\tilde{b}_{j t}-\tilde{b}_{j t}^{*}=-\sum_{l=0}^{t}\left(\frac{1}{\beta}\right)^{l} \frac{1}{\omega_{B}}\left[\left(c_{j, t-l}-c_{j, t-l}^{*}\right)+\tilde{\eta} \omega_{W}\left(\tilde{w}_{j, t-l}-\tilde{w}_{j, t-l}^{*}\right)\right],
$$

the equations characterizing the optimal decisions under perfect information

$$
\begin{aligned}
& c_{j t}^{*}=\underbrace{A_{1}(L) \varepsilon_{t}^{A}}_{c_{j t}^{A *}}+\underbrace{A_{2}(L) \varepsilon_{t}^{R}}_{c_{j t}^{R *}} \\
& \tilde{w}_{j t}^{*}=\gamma c_{j t}^{*} \\
& \hat{c}_{i j t}^{*}=-\theta \hat{p}_{i t},
\end{aligned}
$$

\footnotetext{
${ }^{35}$ In Sections 6-7 it did not matter whether households set real or nominal wage rates since households had perfect information.
} 
the equations characterizing the actual decisions

$$
\begin{aligned}
c_{j t} & =\underbrace{B_{1}(L) \varepsilon_{t}^{A}+C_{1}(L) \nu_{j t}^{A}}_{c_{j t}^{A}}+\underbrace{B_{2}(L) \varepsilon_{t}^{R}+C_{2}(L) \nu_{j t}^{R}}_{c_{j t}^{R}} \\
\tilde{w}_{j t} & =\gamma c_{j t} \\
\hat{c}_{i j t} & =-\tilde{\theta}\left(\hat{p}_{i t}+\frac{\operatorname{Var}\left(\hat{p}_{i t}\right)}{\xi} \nu_{i j t}^{I}\right),
\end{aligned}
$$

and the constraint on information flow

$$
\mathcal{I}\left(\left\{c_{j t}^{A *}, c_{j t}^{R *}, \hat{c}_{1 j t}^{*}, \ldots, \hat{c}_{I-1 j t}^{*}\right\} ;\left\{c_{j t}^{A}, c_{j t}^{R}, \hat{c}_{1 j t}, \ldots, \hat{c}_{I-1 j t}\right\}\right) \leq \kappa .
$$

Here $A_{1}(L), A_{2}(L), B_{1}(L), B_{2}(L), C_{1}(L)$ and $C_{2}(L)$ are infinite-order lag polynomials. The noise terms $\nu_{j t}^{A}, \nu_{j t}^{R}$ and $\nu_{i j t}^{I}$ in the actual decisions are assumed to follow Gaussian white noise processes with unit variance that are: (i) independent of all other stochastic processes in the economy, (ii) household-specific, and (iii) independent of each other. The operator $\mathcal{I}$, defined in equation (83), measures the amount of information that the household's actual decisions contain about the household's optimal decisions under perfect information. Finally, $E_{j,-1}$ in objective (100) is the expectation operator conditioned on the information of household $j$ in period -1 .

The objective (100) states that households aim to maximize the expected discounted sum of period utility net of the cost of information flow. The first term in curly brackets is the expected discounted sum of utility losses in the case of deviations of the actual decisions from the optimal decisions under perfect information. This term equals the right-hand side of equation (49) in Proposition 2. ${ }^{36}$ The second term in curly brackets is the cost of information flow. The parameter $\lambda \geq 0$ is the per-period marginal cost of information flow. We interpret this cost as an opportunity cost. Devoting more attention to the questions of how much to consume, which goods to consume, and which wage to set requires paying less attention to some other decision that we do not model, e.g., the question of where to send the children to school. The variable $\kappa \geq 0$ is the total information

\footnotetext{
${ }^{36}$ Proposition 2 states that, after the log-quadratic approximation to expected lifetime utility and for sequences satisfying conditions (46)-(48), maximizing expected lifetime utility is equivalent to maximizing the expression on the right-hand side of equation (49). When we solve the households' attention problem (100)-(109), we consider only stochastic processes for real bond holdings, the real wage rate, and the consumption mix that satisfy conditions (46)-(48). It is important to note that conditions (46)-(48) do not require that the processes for real bond holdings, the real wage rate, and the consumption mix are stationary. Conditions (46)-(48) do require that second moments increase less than exponentially in $t$.
} 
flow devoted to the intertemporal consumption decision, the consumption mix decision, and the wage setting decision.

If the household chooses a consumption level or a wage rate that differ from the choices the household would have made under perfect information, then bond holdings of the household differ from the bond holdings the household would have had under perfect information. Equation (102) specifies by how much. Equation (102) follows from the flow budget constraint (55) given in Proposition $2 .{ }^{37}$

Equations (103)-(105) characterize the household's optimal decisions under perfect information. These are the decisions that the household would take if the household had perfect information in each period $t \geq 0$. We guess that the optimal composite consumption under perfect information given by equation (52) in Proposition 2 has the representation (103) after substituting in the equilibrium law of motion for $r_{t}$ and $\pi_{t}$. The guess will be verified. The optimal real wage rate under perfect information and the optimal consumption mix under perfect information given by equations (53) and (54) in Proposition 2 reduce to equations (104) and (105) after substituting in $\psi=0$ and equation (59).

Equations (106)-(108) characterize the household's actual decisions. Consider first equation (106). By choosing the lag polynomials $B_{1}(L), C_{1}(L), B_{2}(L)$ and $C_{2}(L)$, the household chooses the stochastic process for composite consumption. For example, if the household chooses $B_{1}(L)=$ $A_{1}(L), C_{1}(L)=0, B_{2}(L)=A_{2}(L)$ and $C_{2}(L)=0$, the household decides to take the optimal consumption decision in each period. The basic trade-off is the following. Choosing a process for composite consumption that tracks more closely optimal composite consumption under perfect information reduces utility losses due to suboptimal consumption-saving decisions but requires more attention. Next, consider equation (107). The equation states that the household sets the real wage rate equal to the marginal rate of substitution between consumption and leisure in each period. The idea behind equation (107) is that information contained in the household's current and past consumption decisions is also used in the household's current wage setting decision. More formally, in Maćkowiak and Wiederholt (2010), Appendix E, we show analytically that if the household can choose the process for the real wage rate as a time-invariant one-sided linear filter of the process for consumption, then the optimal filter is $\tilde{w}_{j t}=\gamma c_{j t}$ so long as the household has linear disutility of

\footnotetext{
${ }^{37}$ Since equation (55) is the log-linearized flow budget constraint, equation (102) determines log bond holdings.
} 
labor $(\psi=0)$. Finally, consider equation (108). By choosing the coefficients $\tilde{\theta}$ and $\xi$, the household chooses the price elasticity of demand and the signal-to-noise ratio in the consumption mix decision. The basic trade-off is the following. Choosing a process for the actual consumption mix that tracks more closely the optimal consumption mix under perfect information reduces utility losses due to suboptimal consumption baskets but requires more attention. ${ }^{38}$

Finally, the information flow constraint (109) states that actual decisions containing more information about the optimal decisions under perfect information require a larger information flow.

To complete the description of the decision problem (100)-(109), we have to specify the expectation operator $E_{j,-1}$ in objective (100). We assume that households have perfect information up to and including period -1 and the particular realization of shocks up to and including period -1 is that shocks are zero. We make this assumption for two reasons. First, this assumption is consistent with the assumption made in Section 2 that all households have the same initial bond holdings. Second, this assumption implies that all discounted second moments in objective (100) are finite even when $\left(x_{t}-x_{t}^{*}\right)$ has a unit root. We want to allow for the possibility that deviations of the actual decisions from the optimal decisions under perfect information have a unit root.

Two remarks are in place before we present solutions of the decision problem (100)-(109). When we solve the decision problem (100)-(109) numerically, we turn this infinite-dimensional problem into a finite-dimensional problem by parameterizing each infinite-order lag polynomial $B_{1}(L), C_{1}(L), B_{2}(L)$ and $C_{2}(L)$ as a lag-polynomial of an ARMA(p,q) process where $p$ and $q$ are finite. $^{39}$ Furthermore, we evaluate the right-hand side of equation (83) for a very large but finite $T$.

\footnotetext{
${ }^{38}$ We put more structure on the consumption mix decision than on the intertemporal consumption decision and the wage setting decision. In particular, in equation (108) we express the consumption mix as a function of relative prices rather than fundamental shocks. We do this because from equation (108) we derive the demand function for good $i$ and a demand function specifies demand on and off the equilibrium path. By expressing the consumption mix as a function of relative prices rather than fundamental shocks, we specify relative consumption of good $i$ by household $j$ on and off the equilibrium path.

${ }^{39}$ We set $p=2$ and $q=2$, because we found that increasing $p$ or $q$ further failed to change noticeably the solution. We allow the $\operatorname{ARMA}(p, q)$ process to have a unit root.
} 


\subsection{Computing the equilibrium of the model}

We use an iterative procedure to solve for the rational expectations equilibrium of the model with rational inattention by households and firms. First, we make a guess concerning the law of motion for the profit-maximizing price, $p_{i t}^{*}$, and a guess concerning the law of motion for the utilitymaximizing composite consumption, $c_{j t}^{*}$. Second, we solve the firms' attention problem (75)-(81) and the households' attention problem (100)-(109). Third, we aggregate the individual prices to obtain the price level. We aggregate across households to obtain aggregate composite consumption, $c_{t}=\frac{1}{J} \sum_{j=1}^{J} c_{j t}$, and the real wage index, $\tilde{w}_{t}=\frac{1}{J} \sum_{j=1}^{J} \tilde{w}_{j t}$. Fourth, we compute the law of motion for the nominal interest rate from the Taylor rule (90) and equation (87). Finally, we compute the law of motion for the profit-maximizing price from equation (91) and the law of motion for the utility-maximizing composite consumption from equation (52). If the law of motion for the profitmaximizing price or the law of motion for the utility-maximizing composite consumption differs from our guess, we update the guess until a fixed point is reached..$^{40}$

\subsection{Benchmark parameter values and solution}

We choose the same parameter values as in the benchmark economy in Section 7.3. We have to choose values for five additional parameters: $\omega_{B}, \omega_{W}, \tilde{\eta}, I$, and $\lambda$. These parameters are: the ratio of real bond holdings to consumption in the non-stochastic steady state, the ratio of real wage income to consumption in the non-stochastic steady state, the wage elasticity of labor demand, the number of consumption goods, and the marginal cost of information flow for a household. These five parameters appear in objective (100) or equation (102). For example, $\omega_{B}, \omega_{W}$ and $\tilde{\eta}$ affect how a percentage deviation in consumption and a percentage deviation in the real wage rate translate into a percentage deviation in real bond holdings.

To set the parameters $\omega_{B}$ and $\omega_{W}$, we consider data from the Survey of Consumer Finances (SCF) 2007. We pursue the following strategy for choosing values for $\omega_{B}$ and $\omega_{W}$. First, since we want to base our calibration of $\omega_{B}$ and $\omega_{W}$ on data for "typical" U.S. households, we compute median nominal net worth, median nominal annual income, and median nominal annual wage income for the households in the 40-60 income percentile of the SCF 2007. These three statistics equal $\$ 88400, \$ 47305$, and $\$ 41135$, respectively. We base our calibration of $\omega_{B}$ and $\omega_{W}$ on all

\footnotetext{
${ }^{40}$ One iteration takes about 4 minutes on the machine described in Footnote 18.
} 
households in the middle income quintile rather than on a single household because we are interested in three variables (net worth, income, and wage income) and the household that is the median household according to one variable may be an unusual household according to the other variables. Second, since consumption appears in the denominator of $\omega_{B}$ and $\omega_{W}$ but the SCF has only very limited data on consumption expenditure, we calculate a proxy for consumption expenditure. The assumption underlying the calculation is that consumption expenditure equals after-tax nominal income minus nominal savings, where nominal savings are just large enough to keep real wealth constant at an annual inflation rate of 2.5 percent. Specifically, we apply the 2007 Federal Tax Rate Schedule "Married Filing Jointly" to nominal annual income given above and we deduct 2.5 percent of nominal net worth given above. This proxy for annual consumption expenditure equals $\$ 38782$. Third, we divide annual nominal wage income by four to obtain quarterly nominal wage income. We divide our proxy for annual consumption expenditure by four to obtain quarterly consumption expenditure. Fourth, we set $\omega_{W}$ equal to the ratio of quarterly nominal wage income to our proxy for quarterly consumption expenditure: $\omega_{W}=(10283.75 / 9695.5)=1.06$. We set $\omega_{B}$ equal to the ratio of nominal net worth given above to our proxy for quarterly consumption expenditure: $\omega_{B}=(88400 / 9695.5)=9.12$.

We set the wage elasticity of labor demand to $\tilde{\eta}=4$. In the case of rational inattention by households and firms, decision-makers on the demand side of each market have rational inattention. Therefore, the price elasticity of demand $\tilde{\theta}$ will typically differ from the preference parameter $\theta$ and the wage elasticity of labor demand $\tilde{\eta}$ will typically differ from the technology parameter $\eta$. Throughout the rest of the paper, we set $\tilde{\theta}=4$ and $\tilde{\eta}=4$, and we compute the parameter $\theta$ that yields a price elasticity of demand of $\tilde{\theta}=4$ and we compute the parameter $\eta$ that yields a wage elasticity of labor demand of $\tilde{\eta}=4$. Hence, we interpret the empirical evidence on price elasticities of demand in the Industrial Organization literature as coming from data generated by our model. ${ }^{41}$

We set the number of consumption goods to $I=1000$. The parameter $I$ has no effect on the responses of the household's composite consumption and the household's real wage rate to shocks. The parameter $I$ only affects the household's choice of $\tilde{\theta}$ and $\xi$. Put differently, the parameter $I$ only affects the parameter $\theta$ that yields $\tilde{\theta}=4$.

\footnotetext{
${ }^{41} \mathrm{~A}$ price elasticity of demand of four is within the range of estimates of the price elasticity of demand in the Industrial Organization literature.
} 
We set the marginal cost of information flow for a household equal to the utility equivalent of 0.1 percent of the household's steady state consumption: $\lambda=(0.001) C_{j} * C_{j}^{-\gamma}$. This value for $\lambda$ implies that, in equilibrium, the expected per-period loss in utility due to deviations of composite consumption and of the real wage rate from the optimal decisions under perfect information equals the utility equivalent of 0.06 percent of the household's steady state consumption. In other words, to fully compensate the household for the expected discounted sum of utility losses due to deviations of composite consumption and of the real wage rate from the optimal decisions under perfect information, it would be sufficient to give the household 1/1700 of the household's steady state consumption in every period. We think these utility losses are extremely small.

We first solve the household's attention problem (100)-(109) assuming that aggregate variables and relative prices are given by the equilibrium of the benchmark economy presented in Section 7.3. In other words, we study the optimal allocation of attention of an individual household when decision-makers in firms have rational inattention and all other households have perfect information. Figure 8 shows the impulse responses of composite consumption by the household to a monetary policy shock (upper panel) and to an aggregate technology shock (lower panel). The purple lines with squares are the impulse responses under rational inattention. For comparison, the green lines with circles show what the household would do if the household had perfect information. The impulse responses of consumption to shocks under rational inattention are very different from the impulse responses of consumption to shocks under perfect information. We find this remarkable because for our parameter values the expected per-period loss in utility due to deviations of composite consumption and of the real wage rate from the optimal decisions under perfect information equals the utility equivalent of only 0.06 percent of the household's steady state consumption. The impulse response of consumption to a monetary policy shock is hump-shaped under rational inattention, while the impulse response of consumption to a monetary policy shock is monotonic under perfect information. Note that after a shock to fundamentals composite consumption under rational inattention differs from composite consumption under perfect information, but in the long run the difference between the two impulse responses goes to zero. Similarly, after a shock to fundamentals real bond holdings under rational inattention differ from real bond holdings under perfect information, but in the long run the difference between the two impulse responses (not 
reported here) goes to zero. ${ }^{42}$ In summary, under rational inattention the consumption level of a household responds very slowly to shocks even when the marginal cost of information flow is small.

If the household had perfect information in each period, then composite consumption of the household would equal the sum of current and future real interest rates (i.e., the long rate). The fact that the household responds very slowly with composite consumption to shocks reflects the fact that the household decides to track movements in the real interest rate imperfectly. One might think that the result that a rational inattention household pays little attention to the real interest rate is due to the fact that the coefficient of relative risk aversion is low, implying that deviations from the consumption Euler equation are cheap in utility terms. Therefore, we studied what happens when we increase $\gamma$ by a factor of 10 from our benchmark value of $\gamma=1$. As $\gamma$ increases from 1 to 10, the attention devoted to the intertemporal consumption decision increases by 50 percent and the ratio of the actual response to the optimal response of consumption on impact of a monetary policy shock increases from 12 percent to 26 percent. The household devotes more attention to the intertemporal consumption decision and therefore consumption responds faster to a monetary policy shock. However, even when $\gamma=10$ the household pays little attention to the intertemporal consumption decision and consumption responds slowly to a monetary policy shock. This is because there are two effects working in opposite directions. Increasing $\gamma$ raises utility losses in the case of deviations of composite consumption from optimal composite consumption under perfect information. See equation (49). This effect raises the attention devoted to the intertemporal consumption decision. On the other hand, increasing $\gamma$ lowers the coefficient on the real interest rate in the consumption Euler equation, implying that being aware of movements in the real interest rate becomes less important. See equation (52). This effect lowers the attention devoted to the intertemporal consumption decision. For $\gamma$ between 1 and 10, the first effect dominates, but only slightly.

Next, we present the equilibrium of the model under rational inattention by households and firms. We use the benchmark parameter values. We compute the rational expectations equilibrium using the iterative procedure described in Section 8.2. Figure 9 shows the impulse responses of the

\footnotetext{
${ }^{42}$ We also find that the impulse responses of composite consumption and real bond holdings under rational inattention to the noise terms in equation (106) go to zero in the long run. In the version of the model where all households solve the problem (100)-(109), this finding implies that neither the cross-sectional variance of consumption nor the cross-sectional variance of real bond holdings diverges to infinity.
} 
price level, inflation, aggregate consumption, and the nominal interest rate to a monetary policy shock. How do the impulse responses to a monetary policy shock change when we add rational inattention by households? The impulse response of aggregate consumption to a monetary policy shock becomes hump-shaped. This is because households decide to pay little attention to movements in the real interest rate. Furthermore, the impulse response of the price level to a monetary policy shock becomes even more dampened and delayed compared with the case of rational inattention by firms and perfect information by households. The dampened and delayed response of aggregate consumption to monetary policy shocks makes decision-makers in firms pay even less attention to monetary policy, implying that the price level responds even more slowly to a monetary policy shock. Households' optimal allocation of attention affects firms' optimal allocation of attention.

Figure 10 shows the impulse responses of the price level, inflation, aggregate consumption, and the nominal interest rate to an aggregate technology shock. How do the impulse responses to an aggregate technology shock change when we add rational inattention by households? The main change is that the impulse response of aggregate consumption to an aggregate technology shock becomes stronger on impact but more persistent. The reason for the stronger consumption response on impact is that the Taylor rule dictates the central bank to lower the nominal interest rate more strongly in response to an aggregate technology shock. This shifts up the consumption response. The change in the persistence of consumption is important quantitatively. In the case of rational inattention by firms and perfect information by households, the growth rate of aggregate consumption conditional on an aggregate technology shock has a serial correlation of 0.38. When we add rational inattention by households, this number more than doubles, to 0.77. Carroll, Slacalek and Sommer (2008) estimate that the growth rate of aggregate consumption has a serial correlation of about 0.7 , on average across countries. Their estimate for the U.S. is 0.83 . This means that, once we add rational inattention by households, the model can match the large serial correlation of aggregate consumption growth in the data.

\subsection{The effects of changes in parameter values}

When we recompute the experiments reported in Section 7.4 with rational inattention by households and firms, we obtain two main findings. The first finding is qualitative. We confirm that changes in the conduct of monetary policy yield very different outcomes in this model than in models 
currently used at central banks because systematic changes in policy cause reallocation of attention by decision-makers in households and firms. The second finding is quantitative. The outcome of a particular experiment can change in an important way after one adds rational inattention by households.

Recall that in Section 7.4 we pointed out two effects of an increase in the coefficient on inflation in the Taylor rule on the variance of the output gap. First, there is the standard effect. As $\phi_{\pi}$ increases, the nominal interest rate mimics more closely the real interest rate at the efficient solution. Second, there is the effect due to the optimal allocation of attention by decision-makers in firms. As $\phi_{\pi}$ increases, decision-makers in firms decide to pay less attention to aggregate conditions. In Section 7.4, we found that in the case of monetary policy shocks the second effect dominates for values of $\phi_{\pi}$ above 1.75: the variance of the output gap due to monetary policy shocks is constant until $\phi_{\pi}=1.75$ and then rises. When we add rational inattention by households, a third effect arises. As $\phi_{\pi}$ increases, the amount of attention that households allocate to aggregate conditions first rises and then falls. The amount of attention that decision-makers in firms allocate to aggregate conditions still falls monotonically. The net effect is the following. In equilibrium, the standard deviation of the output gap due to monetary policy shocks first rises, peaking at $\phi_{\pi}=1.5$, and then falls.

Furthermore, recall that in Section 7.4 we found that, as $\phi_{\pi}$ increases, the standard deviation of the output gap due to aggregate technology shocks first rises, peaking at 1.75 , and then falls. After adding rational inattention by households, we find that the peak occurs at $\phi_{\pi}=3$. The same three effects interact: the standard effect, the effect that decision-makers in firms pay less attention to aggregate conditions when $\phi_{\pi}$ increases, and the effect that the attention devoted by households to aggregate conditions varies non-monotonically with $\phi_{\pi}$.

These findings show that both rational inattention by decision-makers in firms and rational inattention by households can be important for the outcomes of experiments.

\subsection{Extension: Households set nominal wage rates}

We have also solved the model assuming households set nominal wage rates instead of real wage rates. See Sections 8.3 and 8.4 in Maćkowiak and Wiederholt (2010). The main change is that rational inattention by households now also causes deviations from the households' intratemporal 
optimality condition stating that the real wage rate should equal the marginal rate of substitution between consumption and leisure. This has two implications. First, since inattention to aggregate conditions now also causes deviations from the households' intratemporal optimality condition, households decide to pay somewhat more attention to aggregate conditions. This effect tends to make the response of aggregate consumption to shocks somewhat stronger and faster. On the other hand, since households set nominal wage rates instead of real wage rates and households pay limited attention to aggregate conditions, the response of wage rates to shocks becomes more dampened and delayed. This effect increases real effects of monetary policy shocks and increases the distance between the actual response and the efficient response of output to an aggregate technology shock. We chose to present the results with households setting real wage rates here because we think that this version of the model exhibits in the most transparent way the effects of rational inattention by households on the consumption-saving decision.

\section{Conclusion}

We have developed and solved a DSGE model in which decision-makers in households and firms have a limited amount of attention and decide themselves how to allocate their attention. We find that impulse responses to aggregate shocks display substantial inertia, despite the fact that utility losses and profit losses due to rational inattention to aggregate conditions are small. This finding suggests that inertia usually modeled with habit formation in consumption, Calvo price setting, and Calvo wage setting may have a different origin. Furthermore, our model stands in stark contrast to standard business cycle models when it comes to the outcome of policy experiments, the mix of quick and slow responses of prices to shocks, and profit losses due to deviations of the actual price from the profit-maximizing price.

Much work remains ahead. The next step will be to add capital to the model and to estimate the two parameters governing slow adjustment: the marginal cost of attention for a household and the marginal cost of attention for the decision-maker in a firm. 


\section{A Non-stochastic steady state}

In this appendix, we characterize the non-stochastic steady state of the economy described in Section 2. We define a non-stochastic steady state as an equilibrium of the non-stochastic version of the economy with the property that real quantities, relative prices, the nominal interest rate and inflation are constant over time. In the following, variables without the subscript $t$ denote values in the non-stochastic steady state.

In this appendix, $P_{t}$ denotes the following price index

$$
P_{t}=\left(\sum_{i=1}^{I} P_{i t}^{1-\theta}\right)^{\frac{1}{1-\theta}}
$$

and $W_{t}$ denotes the following wage index

$$
W_{t}=\left(\sum_{j=1}^{J} W_{j t}^{1-\eta}\right)^{\frac{1}{1-\eta}}
$$

In the non-stochastic steady state, the households' first-order conditions read

$$
\begin{gathered}
\frac{R}{\Pi}=\frac{1}{\beta}, \\
\frac{C_{i j}}{C_{j}}=\hat{P}_{i}^{-\theta},
\end{gathered}
$$

and

$$
\tilde{W}_{j}=\varphi\left(\hat{W}_{j}^{-\eta} L\right)^{\psi} C_{j}^{\gamma}
$$

The firms' first-order conditions read

$$
\hat{P}_{i}=\tilde{W} \frac{1}{\alpha}\left(\hat{P}_{i}^{-\theta} C\right)^{\frac{1}{\alpha}-1},
$$

and

$$
\hat{L}_{i j}=\hat{W}_{j}^{-\eta}
$$

The firms' price setting equation (115) implies that all firms set the same price in the nonstochastic steady state. Households therefore consume the different consumption goods in equal amounts, implying that all firms produce the same amount. Since in addition all firms have the same technology in the non-stochastic steady state, all firms have the same composite labor input. 
It follows from the definition of the price index (110), the consumption aggregator (2) and the definition of aggregate composite labor input (13) that

$$
\hat{P}_{i}^{1-\theta}=\left(\frac{C_{i j}}{C_{j}}\right)^{\frac{\theta-1}{\theta}}=\frac{L_{i}}{L}=\frac{1}{I} .
$$

Furthermore, in the non-stochastic version of the economy, all households face the same decision problem, have the same information and their decision problem has a unique constant solution, implying that all households choose the same consumption vector and set the same wage rate in the non-stochastic steady state. Firms therefore hire the different types of labor in equal amounts. It follows from the definition of aggregate composite consumption (12), the definition of the wage index (111) and the labor aggregator (5) that

$$
\frac{C_{j}}{C}=\hat{W}_{j}^{1-\eta}=\hat{L}_{i j}^{\frac{\eta-1}{\eta}}=\frac{1}{J} .
$$

One can show that equations (112)-(118), $Y_{i}=L_{i}^{\alpha}$ and $Y_{i}=\hat{P}_{i}^{-\theta} C$ imply that all variables appearing in equations (112)-(118) are uniquely determined apart from the nominal interest rate, $R$, and inflation, $\Pi$. For ease of exposition, we select $\Pi=1$. Equation (112) then implies $R=(1 / \beta)$. Furthermore, the initial price level, $P_{-1}$, is not determined. We assume that $P_{-1}$ equals some value $\bar{P}_{-1}$. For given initial real bond holdings $\left(B_{j,-1} / \bar{P}_{-1}\right)$, fiscal variables in the non-stochastic steady state are uniquely determined by the requirement that real quantities are constant over time. The reason is that real bond holdings are a real quantity and real bond holdings are constant over time if and only if the government runs a balanced budget in real terms (i.e., real lump-sum taxes equal the sum of real interest payments and real subsidy payments). 


\section{References}

[1] Altig, David, Lawrence Christiano, Martin Eichenbaum and Jesper Linde (2005): "FirmSpecific Capital, Nominal Rigidities and the Business Cycle." NBER Working Paper 11034.

[2] Angeletos, George-Marios, and Jennifer La'O (2009a): "Incomplete Information, Higher-Order Beliefs and Price Inertia." Journal of Monetary Economics, 56(S), 19-37.

[3] Angeletos, George-Marios, and Jennifer La'O (2009b): "Noisy Business Cycles." NBER Macroeconomics Annual 2009, 319-378.

[4] Ball, Lawrence, and David Romer (1990): "Real Rigidities and the Non-Neutrality of Money." Review of Economic Studies, 57(2), 183-203.

[5] Bils, Mark, Peter J. Klenow and Benjamin A. Malin (2009): "Reset Price Inflation and the Impact of Monetary Policy Shocks." Discussion paper, University of Rochester, Stanford University, and Federal Reserve Board.

[6] Boivin, Jean, Marc Giannoni and Ilian Mihov (2009): "Sticky Prices and Monetary Policy: Evidence from Disaggregated U.S. Data.” American Economic Review, 99(1), 350-384.

[7] Carroll, Christopher D., Jirka Slacalek and Martin Sommer (2008): "International Evidence on Sticky Consumption Growth.” NBER Working Paper 13876.

[8] Christiano, Lawrence J., Martin Eichenbaum and Charles L. Evans (1999): "Monetary Policy Shocks: What Have We Learned and to What End?" In "Handbook of Macroeconomics", edited by John B. Taylor and Michael Woodford, Elsevier, New York.

[9] Christiano, Lawrence J., Martin Eichenbaum and Charles L. Evans (2005): "Nominal Rigidities and the Dynamic Effects of a Shock to Monetary Policy." Journal of Political Economy, 113(1), $1-45$.

[10] Dixit, Avinash, and Joseph E. Stiglitz (1977): "Monopolistic Competition and Optimum Product Diversity." American Economic Review, 67(3), 297-308.

[11] Hellwig, Christian, and Laura Veldkamp (2009): "Knowing What Others Know: Coordination Motives in Information Acquisition.” Review of Economic Studies, 76(1), 223-251. 
[12] Hellwig, Christian, and Venky Venkateswaran (2009): "Setting the Right Prices for the Wrong Reasons." Journal of Monetary Economics, 56(S), 57-77.

[13] Justiniano, Alejandro, and Giorgio Primiceri (2008): "The Time Varying Volatility of Macroeconomic Fluctuations." American Economic Review, 98(3), 604-641.

[14] Kacperczyk, Marcin, Stijn Van Nieuwerburgh and Laura Veldkamp (2010): "Attention Allocation over the Business Cycle." Discussion paper, NYU.

[15] Klenow, Peter J., and Oleksiy Kryvtsov (2008): "State-Dependent or Time-Dependent Pricing: Does It Matter for Recent U.S. Inflation?" Quarterly Journal of Economics, 123(3), 863-904.

[16] Leeper, Eric M., Christopher A. Sims and Tao Zha (1996): "What Does Monetary Policy Do?" Brookings Papers on Economic Activity, 1996(2), 1-63.

[17] Lucas, Robert E. Jr. (1972): "Expectations and the Neutrality of Money." Journal of Economic Theory, 4(2), 103-124.

[18] Luo, Yulei (2008): "Consumption Dynamics under Information Processing Constraints." Review of Economic Dynamics, 11(2), 366-385.

[19] Lorenzoni, Guido (2009): "A Theory of Demand Shocks." American Economic Review, 99(5), 2050-2084.

[20] Maćkowiak, Bartosz, Emanuel Moench and Mirko Wiederholt (2009): "Sectoral Price Data and Models of Price Setting." Journal of Monetary Economics, 56(S), 78-99.

[21] Maćkowiak, Bartosz, and Mirko Wiederholt (2009): "Optimal Sticky Prices under Rational Inattention." American Economic Review, 99(3), 769-803.

[22] Maćkowiak, Bartosz, and Mirko Wiederholt (2010): "Business Cycle Dynamics under Rational Inattention." CEPR Discussion Paper 7691.

[23] Mankiw, N. Gregory, and Ricardo Reis (2002): "Sticky Information versus Sticky Prices: A Proposal to Replace the New Keynesian Phillips Curve." Quarterly Journal of Economics, $117(4), 1295-1328$. 
[24] Matejka, Filip (2010): "Rationally Inattentive Seller: Sales and Discrete Pricing." Discussion paper, Princeton University.

[25] Mondria, Jordi (2010): "Portfolio Choice, Attention Allocation, and Price Comovement." Journal of Economic Theory, forthcoming.

[26] Nakamura, Emi, and Jón Steinsson (2008): "Five Facts About Prices: A Reevaluation of Menu Cost Models." Quarterly Journal of Economics, 123(4), 1415-1464.

[27] Paciello, Luigi (2010): "Monetary Policy Activism and Price Responsiveness to Aggregate Shocks under Rational Inattention." Discussion paper, Einaudi Institute for Economics and Finance.

[28] Rudebusch, Glenn D. (2002): "Term Structure Evidence on Interest Rate Smoothing and Monetary Policy Inertia.” Journal of Monetary Economics 49(6), 1161-1187.

[29] Sims, Christopher A. (2003): "Implications of Rational Inattention." Journal of Monetary Economics, 50(3), 665-690.

[30] Sims, Christopher A. (2006): "Rational Inattention: Beyond the Linear-Quadratic Case." American Economic Review Papers and Proceedings, 96(2), 158-163.

[31] Sims, Christopher A. (2010): "Rational Inattention and Monetary Economics." Prepared for Handbook of Monetary Economics, Elsevier.

[32] Smets, Frank, and Rafael Wouters (2007): "Shocks and Frictions in U.S. Business Cycles: A Bayesian DSGE Approach.” American Economic Review, 97(3), 586-606.

[33] Tutino, Antonella (2009): "The Rigidity of Choice. Lifecycle Savings with Information Processing Limits." Discussion paper, Federal Reserve Board.

[34] Uhlig, Harald (2005): "What Are the Effects of Monetary Policy on Output? Results from an Agnostic Identification Procedure.” Journal of Monetary Economics, 52, 381-419.

[35] Van Nieuwerburgh, Stijn, and Laura Veldkamp (2009): "Information Immobility and the Home Bias Puzzle." Journal of Finance, 64(3), 1187-1215. 
[36] Van Nieuwerburgh, Stijn, and Laura Veldkamp (2010): "Information Acquisition and UnderDiversification." Review of Economic Studies, 77(2), 779-805.

[37] Veldkamp, Laura (2010): Information Choice in Macroeconomics and Finance. Princeton University Press, forthcoming.

[38] Woodford, Michael (2002): "Imperfect Common Knowledge and the Effects of Monetary Policy." In Knowledge, Information, and Expectations in Modern Macroeconomics: In Honor of Edmund S. Phelps, ed. Philippe Aghion et al. Princeton and Oxford: Princeton University Press.

[39] Woodford, Michael (2003): Interest and Prices. Foundations of a Theory of Monetary Policy. Princeton and Oxford: Princeton University Press.

[40] Woodford, Michael (2009): "Information-Constrained State-Dependent Pricing." Journal of Monetary Economics, 56(S), 100-124. 

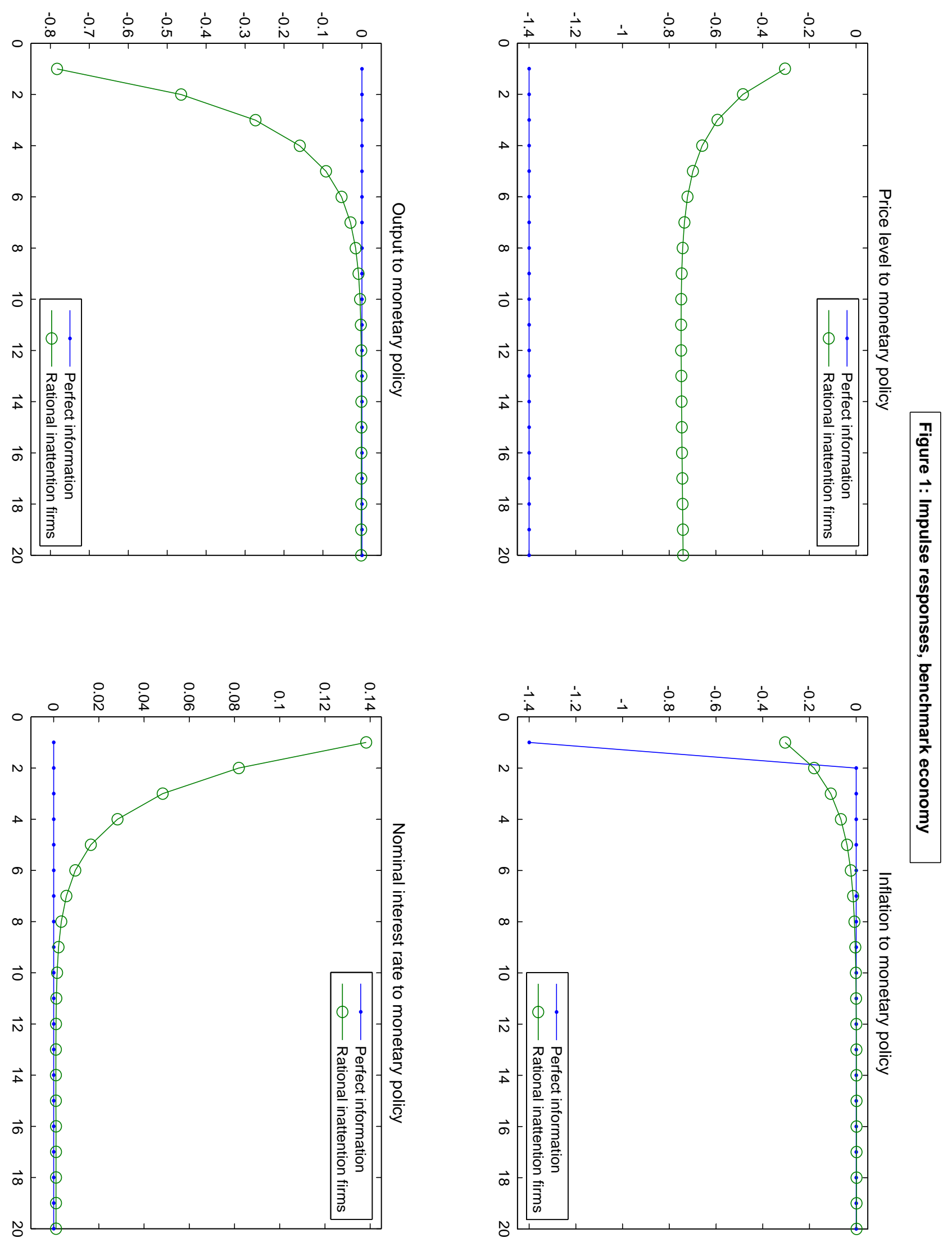

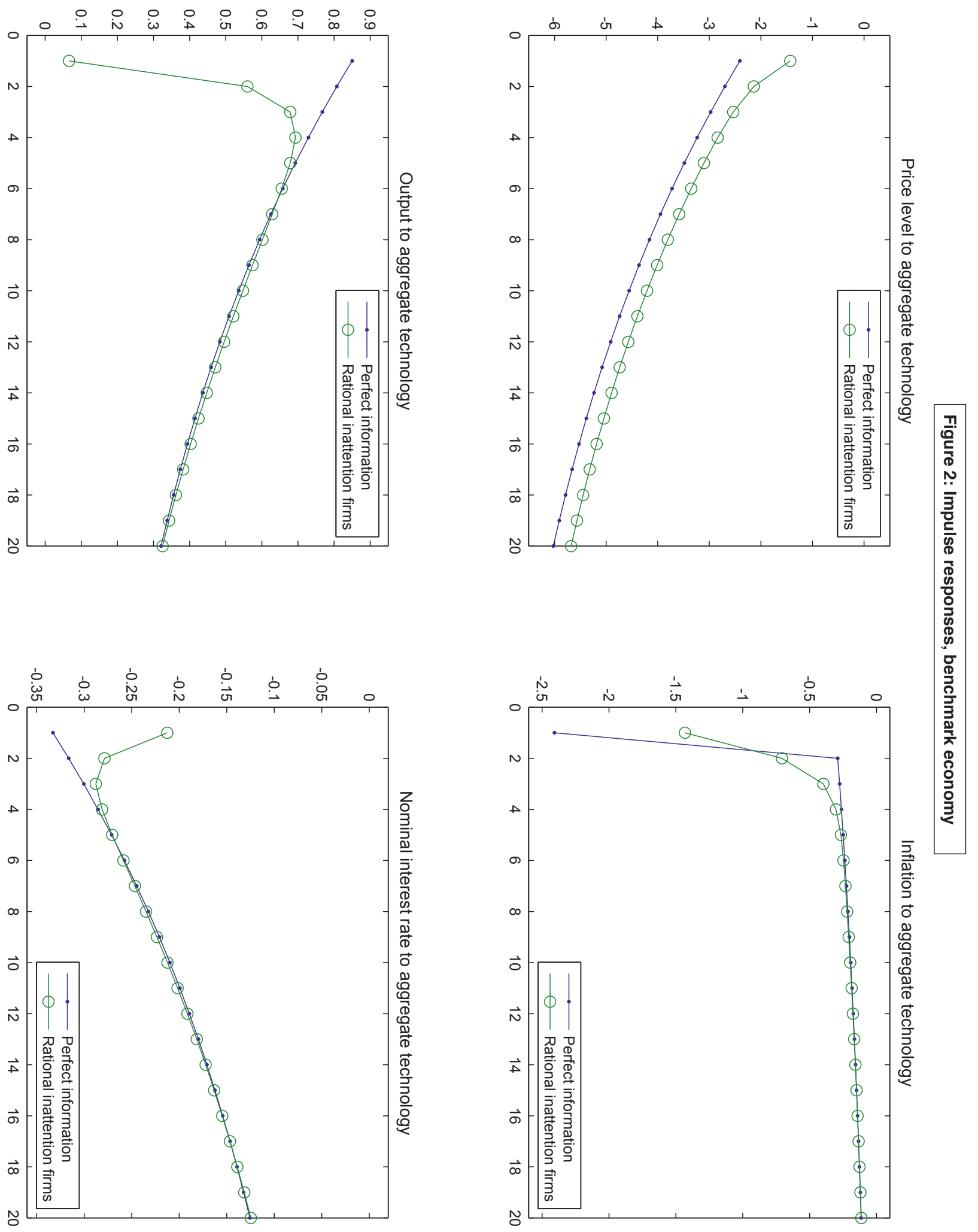


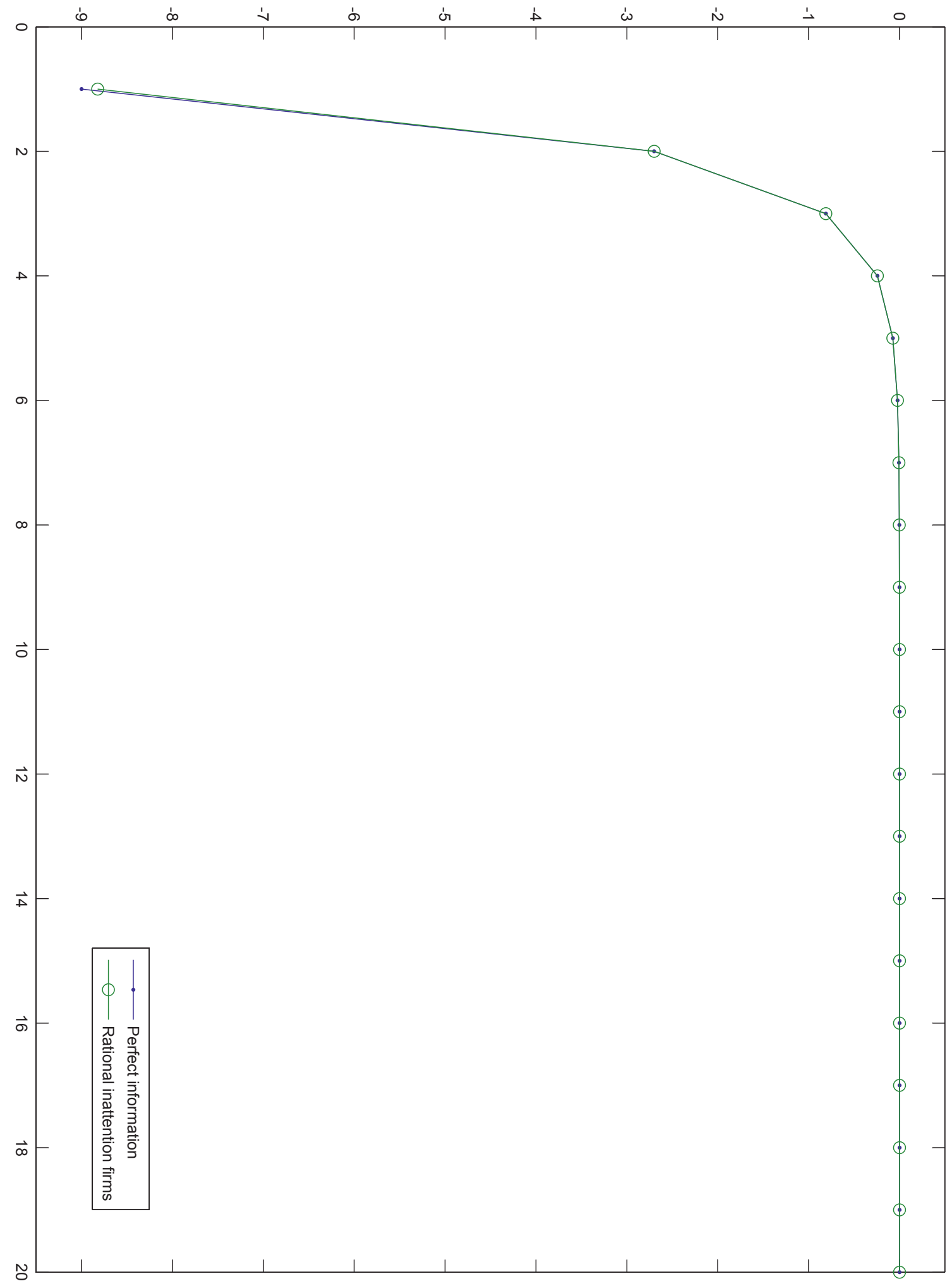

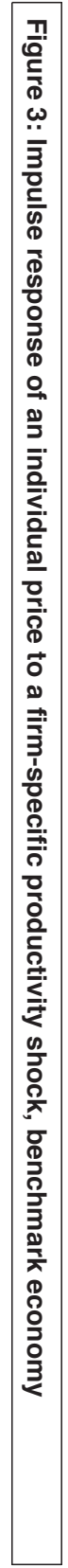



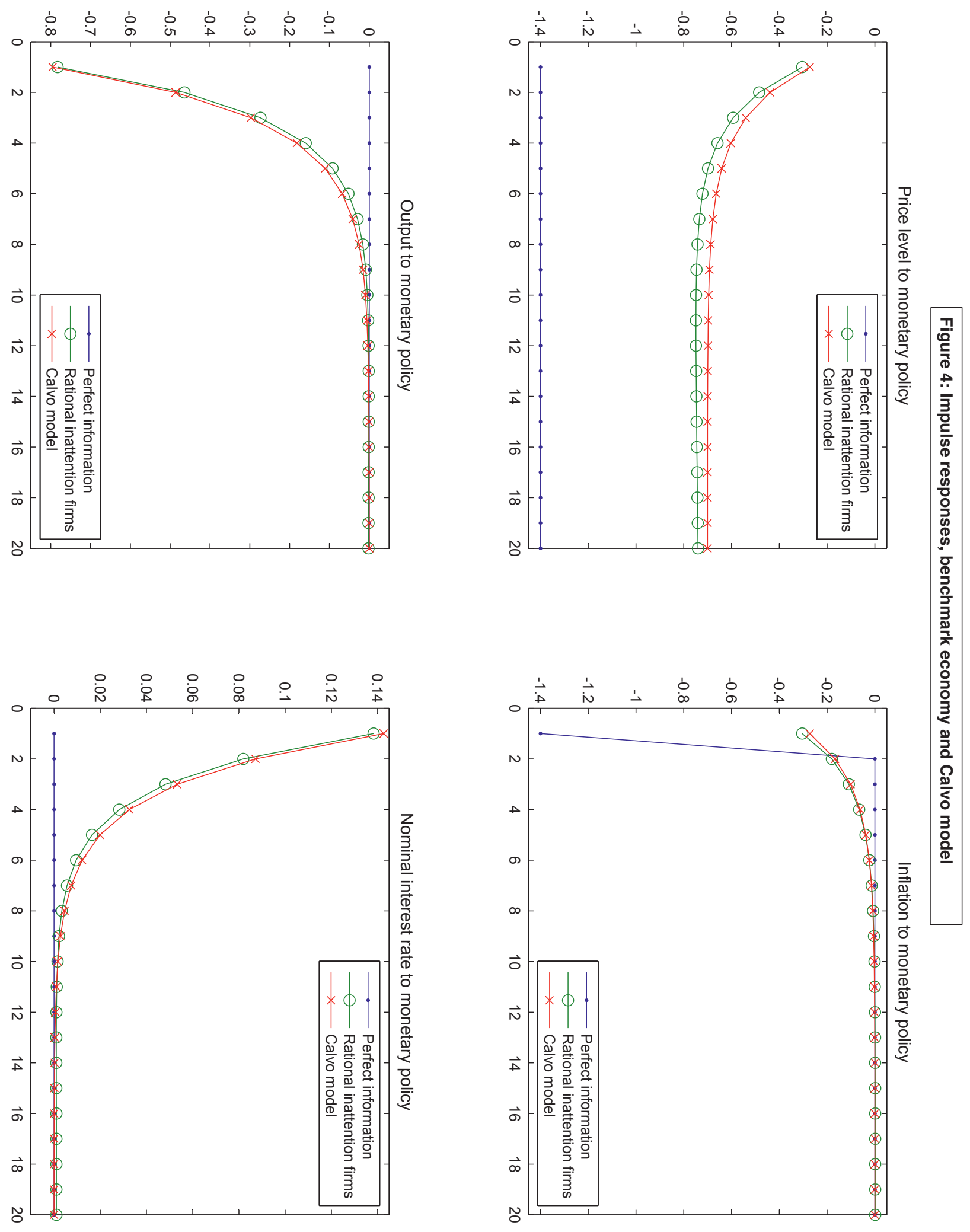

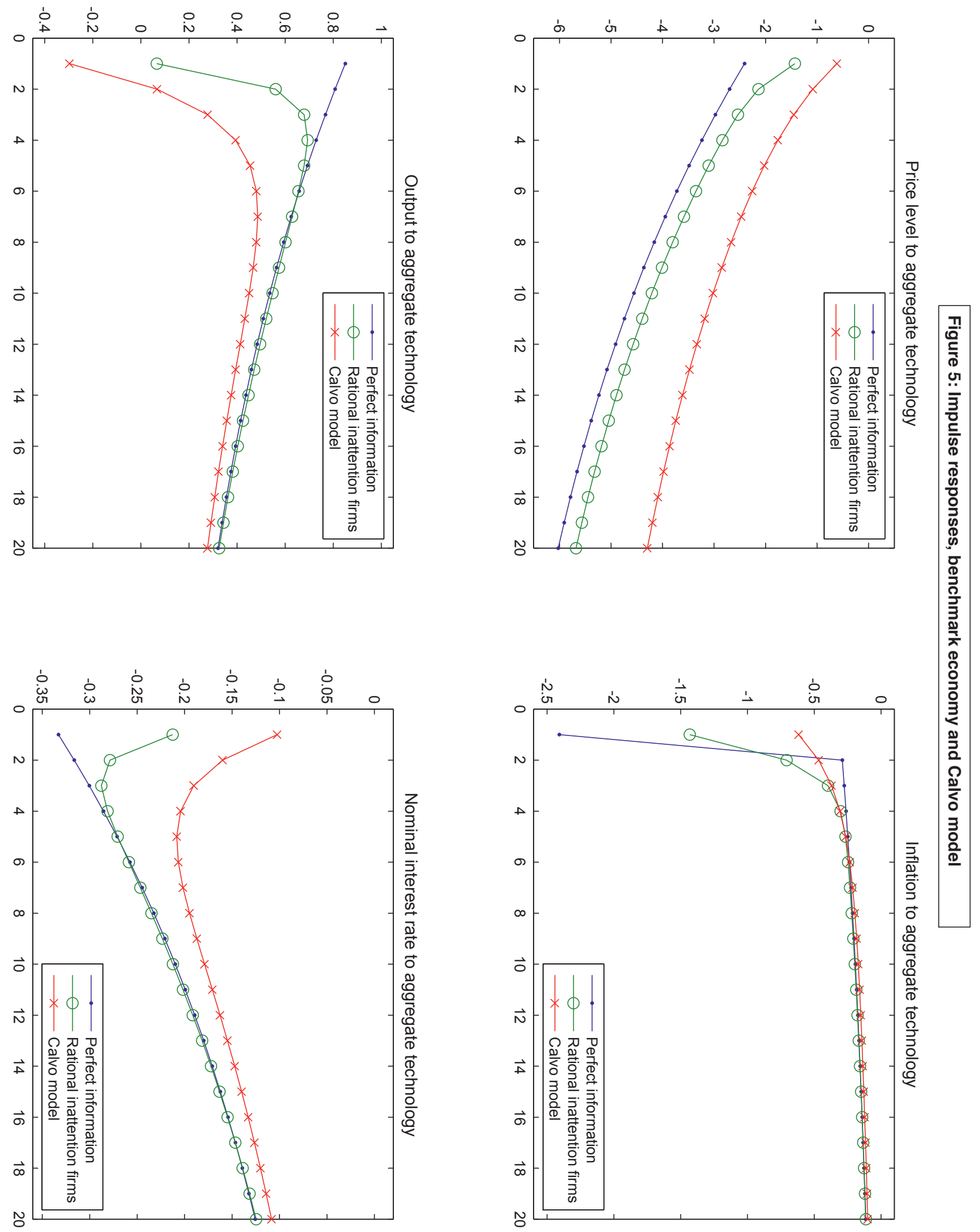

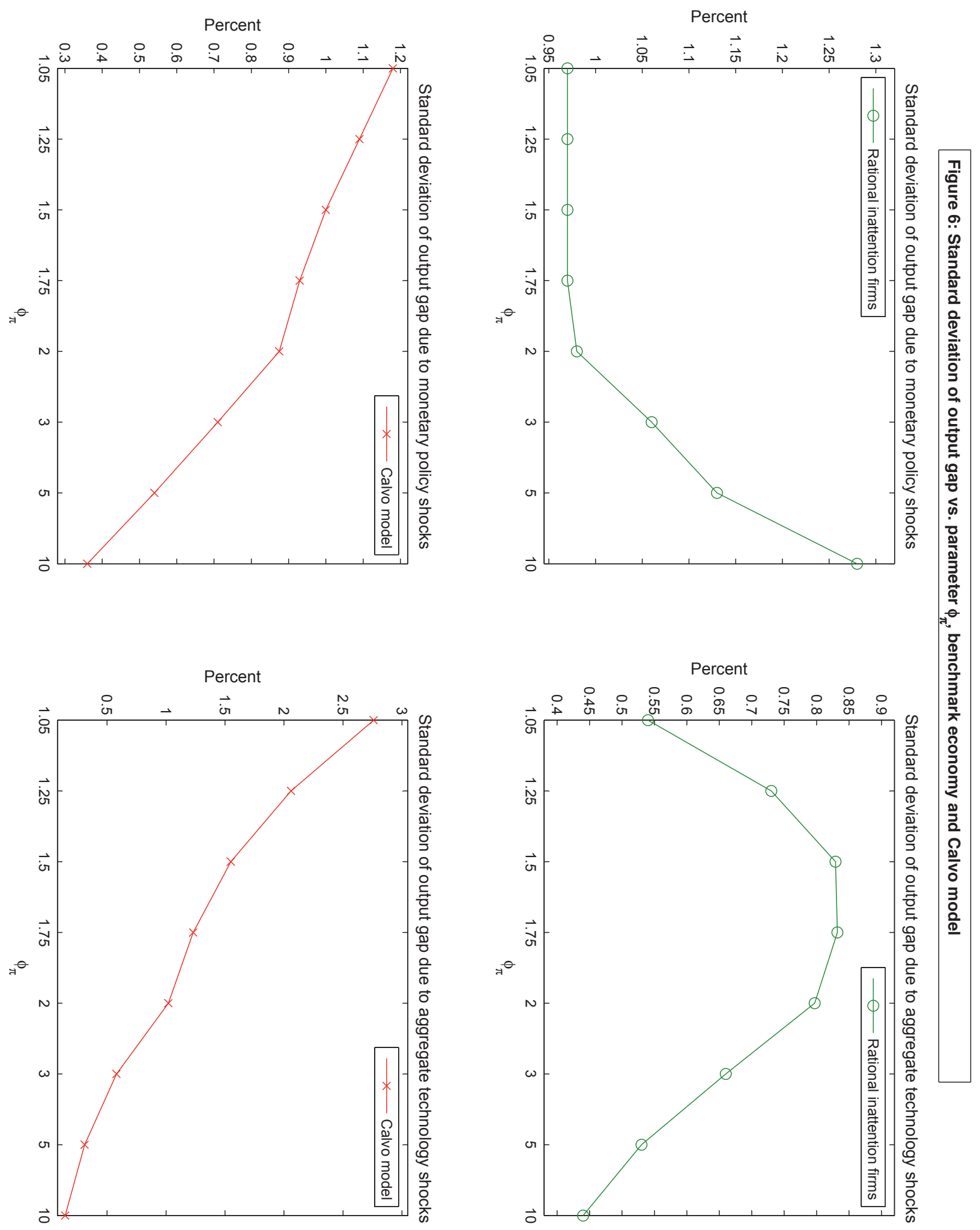

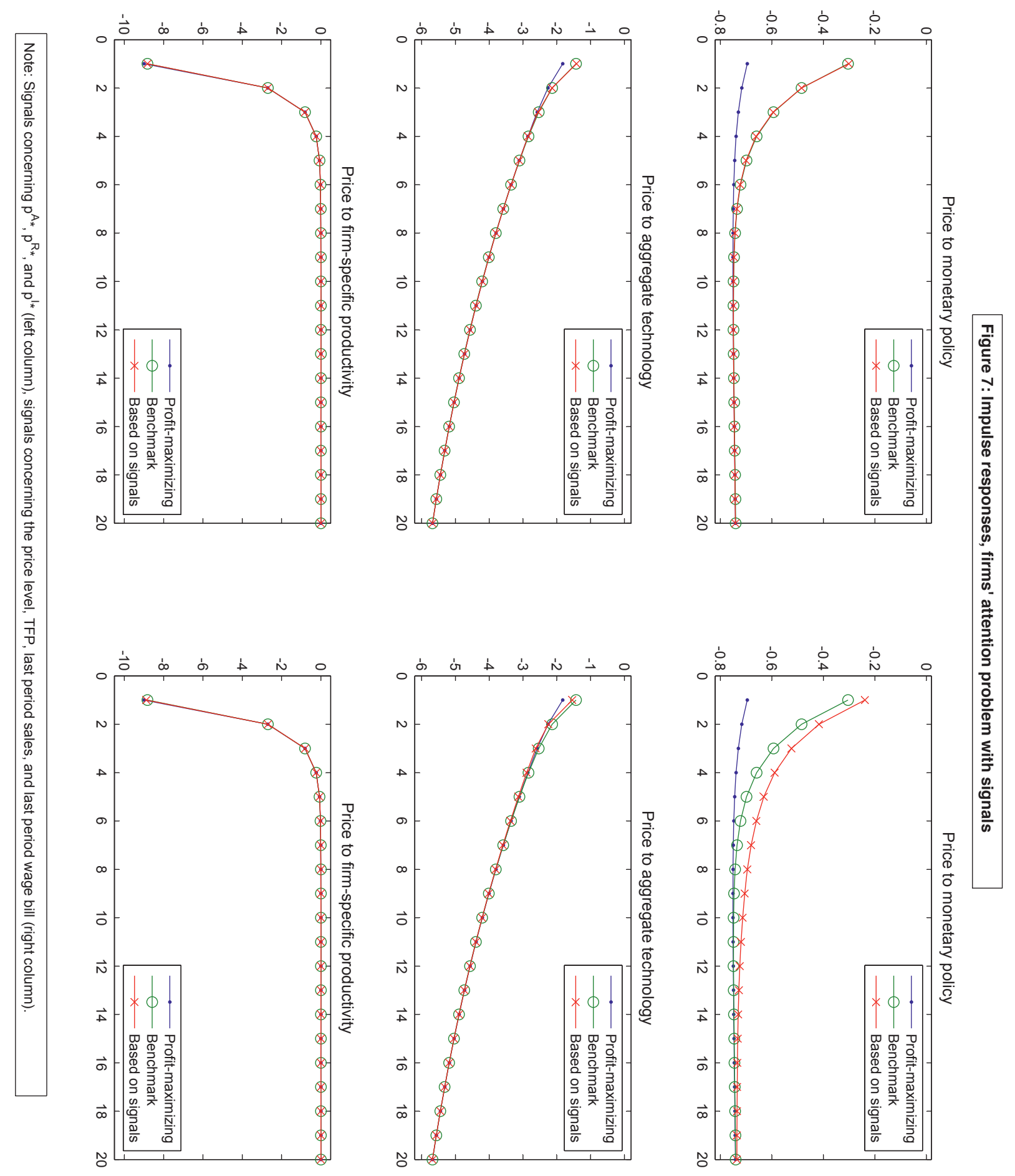

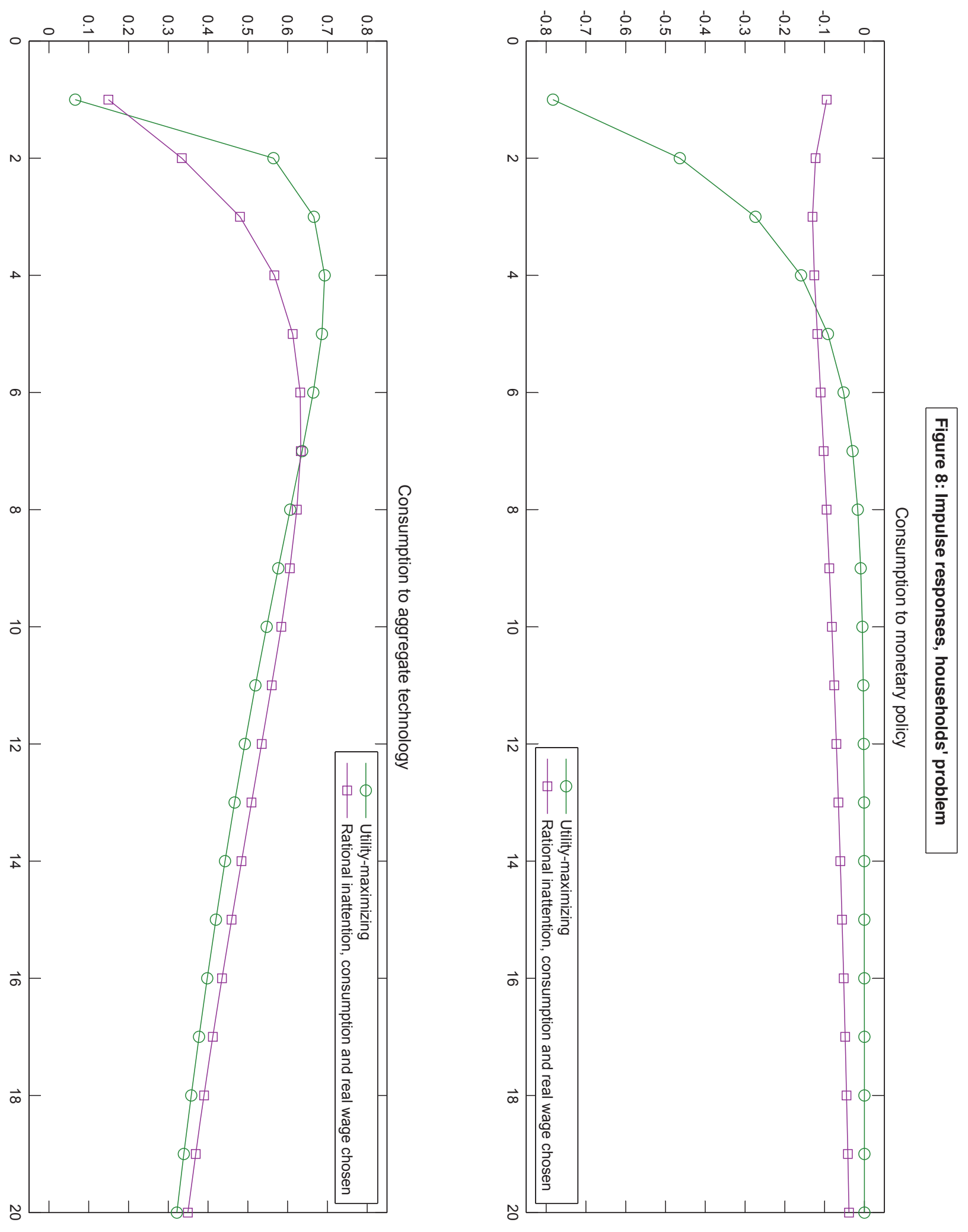

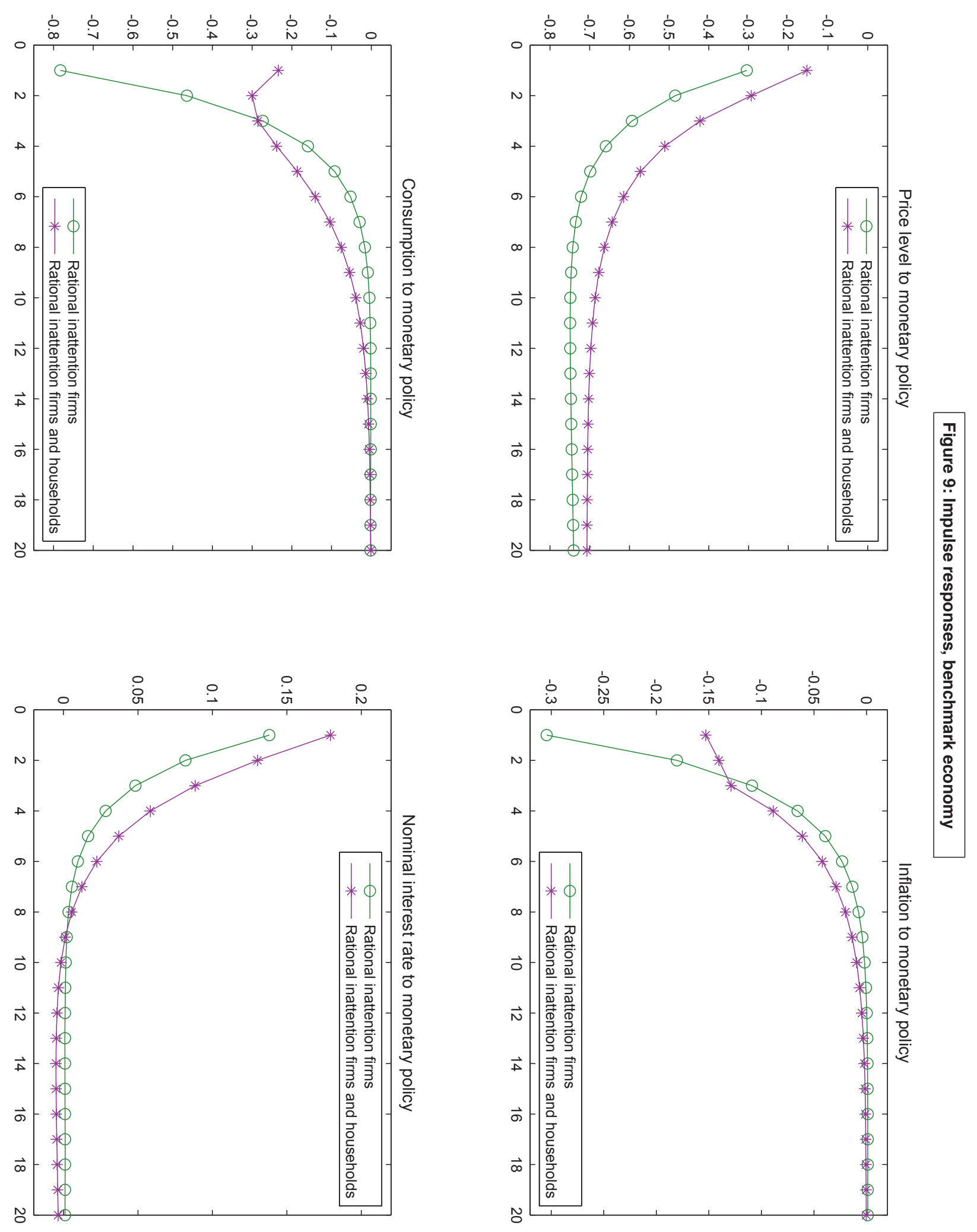

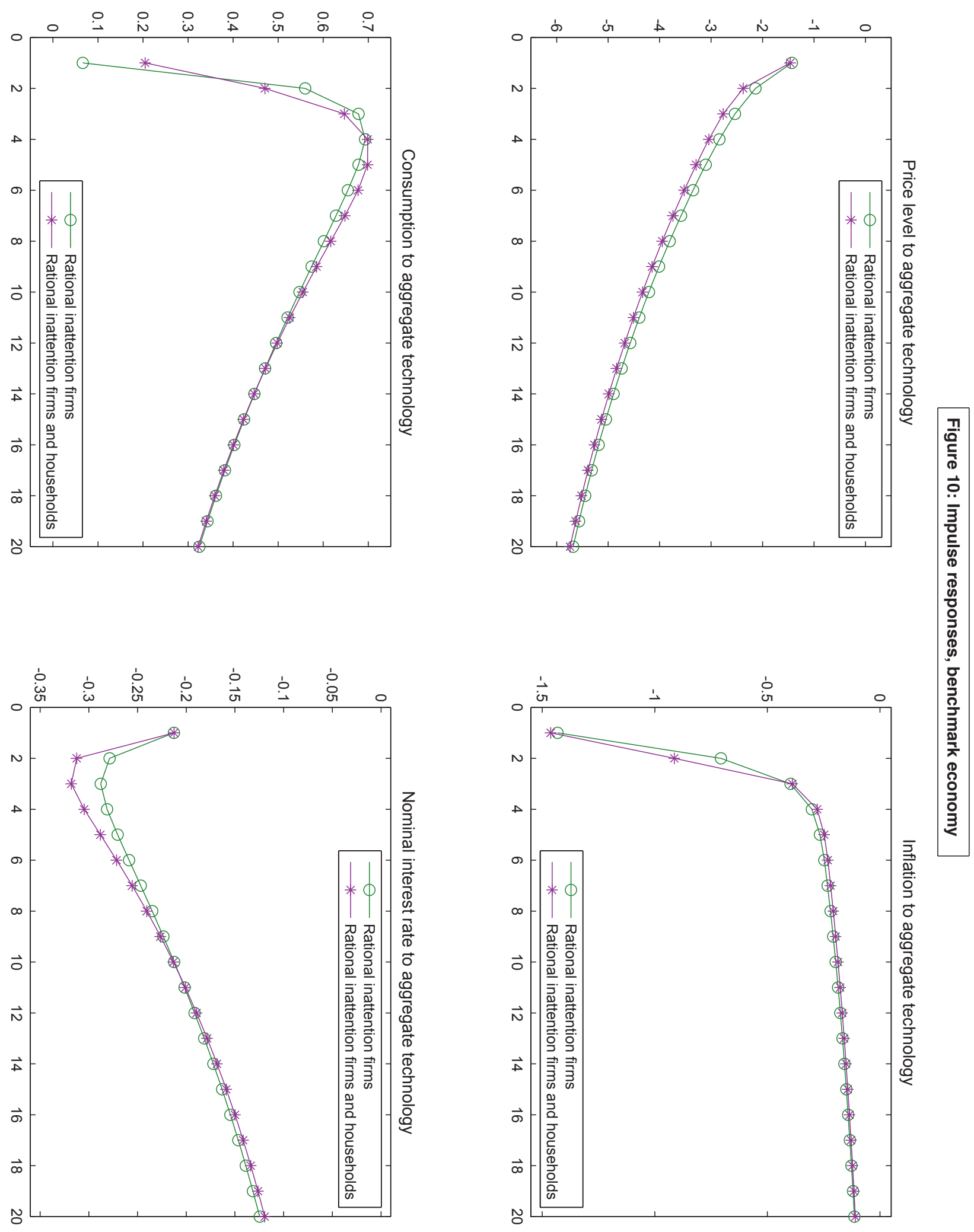
